\title{
Crosstalk of Histone Modifications in the Healthy Human Immune System
}

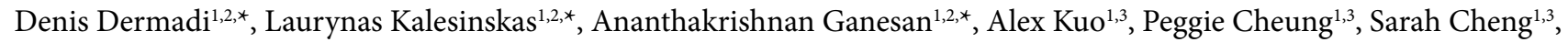 \\ Mei Dvorak ${ }^{1,3}$, Thomas J. Scriba ${ }^{4}$, Aida Habtezion ${ }^{1,5}$, Michele Donato ${ }^{1,2}$, Paul J. Utz ${ }^{1,3 * *}$, Purvesh Khatri ${ }^{1,2, * *}$
}

\begin{abstract}
Chromatin remodeling through post-translational modifications of histone tails (HPTM) is fundamental for regulation and maintenance of DNA-centered processes. Systems level understanding of coordination and interactions between HPTMs and their impact on the functional state of the immune cells remain unexplored due to the technical reasons. We leveraged large biologically heterogeneous data (>27 million cells), comprising of primary human immune cells profiled for 33 HPTMs and 4 histone variants at the single-cell level using high-dimensional mass cytometry (EpiTOF), to discover and map relations between HPTMs at the systems level. Briefly, we elucidated a comprehensive epigenetic network of HPTM interactions, discovered a novel subset of hematopoietic progenitors with distinct epigenetic profile, and revealed hitherto undescribed associations between a decrease in global methylations, modulation of one-carbon metabolism, and immune cell life span. Ultimately our work lays a foundation for future studies aimed at understanding complexity of HPTM interactions in immune response in infectious or autoimmune diseases, cancers, and vaccination.
\end{abstract}

Eukaryotic genetic material is organized into chromatin, a highly revealing spatial and functional roles of PTMs, ChIP-seq is limited structured polymer of DNA and histones $\mathrm{H} 3, \mathrm{H} 4, \mathrm{H} 2 \mathrm{~A}$, and to the measurement of 2-3 histone modifications simultaneously, $\mathrm{H}_{2} \mathrm{~B}^{1}$. Histones feature flanking $\mathrm{N}$-terminal tails that are post- requires large quantities of a sample, and is labor-intensive ${ }^{10}$. translationally modified at lysines, arginines, and serines. Histone Despite the feasibility of ChIP-seq at a single-cell resolution, posttranslational modifications (HPTMs) are largely associated it is still limited to a few thousand single cells and simultaneous with relaxation or compaction of chromatin; therefore, directly detection of at most two HPTMs ${ }^{11,12}$.

impacting regulation, activation, and repression of transcription. Additionally, HPTMs regulate a variety of distinct biological functions and cell states such as DNA damage and repair signaling, maintenance of cell cycle progression, quiescence, and apoptosis. Recent studies have demonstrated complex and nuanced crosstalk between multiple HPTMs, referred to as "histone language", as the basis of transcriptional regulation in response to the environment. Histone language is based on spatial co-localization and the simultaneous presence of 2 or more PTMs on (1) a single histone within a nucleosome (cis histone pathway) and/or (2) PTMs on different histones within the same or adjacent nucleosome (trans histone pathway $)^{3,4}$. For example, phosphorylation of serine 10 (S10) on $\mathrm{H} 3(\mathrm{H} 3 \mathrm{~S} 10 \mathrm{ph})$ promotes the acetylation of H3K14 (H3K14ac) and inhibits methylation of $\mathrm{H} 3 \mathrm{~K} 9$ (H3K9me) on the same histone tail (cis pathway) ${ }^{5,6}$. In contrast, ubiquitination of H2B modulates multiple methylation events on $\mathrm{H} 3$ (trans pathway) ${ }^{7-9}$.

To date, the histone language has been mostly studied in vitro or in lower eukaryotes using direct mutagenesis of sites of histone modifications. Similar experimental designs are very difficult, if not impossible, in vivo and in higher eukaryotes, including humans ${ }^{4}$. Discovery of the histone language has been driven largely by mass spectrometry and ChIP-seq, both gold standards in detecting novel HPTMs and assessing the spatial distribution of modifications across the genome, respectively. However, although unrivaled in

Here, we present the first single-cell resolution study of the nuanced crosstalk between HPTMs in the healthy human immune system using EpiTOF ${ }^{13}$, a high-throughput mass cytometry technology. We profiled 37 HPTMs and histone variants along with 16 cellular phenotypic markers across almost 28 million peripheral blood mononuclear cells (PBMCs) from 5 independent cohorts comprising 83 healthy individuals. The wealth of data at a singlecell resolution presents an unprecedented opportunity to investigate correlations between HPTMs, and the resulting regulatory network, which can potentially reveal novel HPTM interactions in the histone language. Using these data, we (1) elucidated a comprehensive epigenetic network of HPTM interactions in healthy human PBMCs, (2) discovered a previously unreported subset of hematopoietic progenitors with distinct epigenetic profile, and (3) revealed hitherto undescribed associations between a decrease in global cellular methylations, metabolism modulation, and immune cell life span.

\section{Results}

\section{Data collection}

We profiled 27,841,803 PBMCs from 83 healthy individuals across 5 independent cohorts matched for age and sex using EpiTOF. These cohorts included subjects from two continents with ages ranging from 16 years to 80 years old (Table S1). We analyzed

\footnotetext{
${ }^{1}$ Institute for Immunity, Transplantation and Infection, School of Medicine, Stanford University, CA 94305, USA

${ }^{2}$ Center for Biomedical Informatics Research, Department of Medicine, School of Medicine, Stanford University, Stanford, CA 94305, USA

${ }^{3}$ Division of Immunology and Rheumatology, Department of Medicine, School of Medicine, Stanford University, Stanford, CA 94305, USA

${ }^{4}$ South African Tuberculosis Vaccine Initiative, Institute of Infectious Disease and Molecular Medicine and Division of Immunology, Department of

Pathology, University of Cape Town, Cape Town, 7925, South Africa

${ }^{5}$ Stanford University School of Medicine, Division of Gastroenterology and Hepatology, Stanford, CA 94305, USA

${ }^{*}$ Co-first authors

${ }^{\star \star}$ Correspondence: Purvesh Khatri (pkhatri@stanford.edu) or Paul J Utz (pjutz@stanford.edu)
} 
three previously published cohorts from the US (BR1, BR2, S2A-B), and acetylation module 1 (AM1), 2 (AM2), and 3 Twins) ${ }^{13}$, a cohort of healthy adults from the US (Stanford) and (AM3) (Fig. 4A-C, Fig. S3A-C) were present in all immune cell a cohort of adolescents from South Africa (South Africa). We types. MM1 and AM1 were characterized by moderate-to-strong profiled 37 HPTMs and histone variants divided into two panels: one predominantly measures histone methylations (methylation panel), and the other histone acetylations, phosphorylations, and ubiquitinations (acetylation panel). Both panels include 16 phenotypic cell surface markers for immune cells of human peripheral blood ${ }^{13}$. We determined correlations between HPTMs abundances in each major immune cell type in the PBMCs from healthy individuals, including hematopoietic progenitor cells (HPCs), plasmacytoid dendritic cells (pDCs), myeloid dendritic cells (mDCs), natural killer (NK) cells, NKT, B, CD4, and CD8 T cells, classical monocytes (cMOs), intermediate monocytes (iMOs) and non-classical monocytes (ncMOs) (Methods).

\section{Discovery and validation of HTPM correlation modules in healthy immune cells}

We hypothesized that comparison of HPTM correlation networks for each immune cell type will identify differences in epigenetic regulations between them. To test this hypothesis, we used BR1 (7.39 million cells from 12 subjects) as a "discovery" cohort and BR2, Twins, Stanford, and SA ( $>20$ million cells from 71 subjects) as "validation" cohorts. Pairwise Pearson correlations for all HPTMs pairs for 11 immune cell types (HPCs, pDCs, mDCs, NK, NKT, B, CD4, and CD8 T cells, cMOs, iMOs and ncMOs) were highly conserved between discovery (Fig. 1A, Fig. 2A) and 4 independent validation cohorts, irrespective of age and country (Fig. 1B-E, Fig. 2B-E, Methods). Furthermore, we observed significantly higher variance in pairwise HPTM correlations in HPCs and myeloid cells than lymphoid cells (Fig. S1A), suggesting higher epigenetic heterogeneity (Fig. 1F, Fig. 2F, Methods). These consistent, hitherto unobserved, correlations between HPTMs across multiple independent cohorts provide strong evidence of conserved epigenetic regulatory networks in major immune cell types in healthy individuals.

positive correlations, whereas MM2, AM2, and AM3 had weakto-moderate positive correlations. MM1 comprised 14 HPTMs, of which $\mathrm{H} 3 \mathrm{~K} 4 \mathrm{me} 3, \mathrm{H} 3 \mathrm{~K} 9 \mathrm{me} 2$, and $\mathrm{H} 4 \mathrm{~K} 20 \mathrm{me} 2$ were positively correlated with 9 or more HPTMs. Moreover, the highest BC value of $\mathrm{H} 3 \mathrm{~K} 4 \mathrm{me} 3$ and $\mathrm{H} 3 \mathrm{~K} 9 \mathrm{me} 2$ indicated their centrality in MM1 (Fig. 3A, Fig. S2A). These results are in line with previous studies showing that $\mathrm{H} 3 \mathrm{~K} 4 \mathrm{me} 3$ is enriched within active promoters and regulatory elements ${ }^{14}$, whereas $\mathrm{H} 3 \mathrm{~K} 9 \mathrm{me} 2$ is modestly correlated with silenced genes and many active genes show H3K9me2 enrichment at their promoters ${ }^{15}$.

MM2 consisted mostly of weak-to-moderate correlations between 18 HPTMs, of which H3K4me2, H3K9me1, Rme1, H3K27me1, and $\mathrm{H} 3 \mathrm{~K} 27 \mathrm{me} 3$ were the most connected HPTMs. H3K4me2 and H3K9me1 had the highest betweenness centrality (Fig. 3B, Fig. S2B), indicating their importance in signal transduction between HPTMs in MM2. Interestingly, MM2 centered around H3K4me2 and H3K9me1, both HPTMs containing one methyl fewer than the central HPTMs in MM1, suggesting methylations of H3K4 and H3K9 may be regulated at the same time.

AM1 was characterized by strong correlations between 7 HPTMs, of which H4K5ac, H4K16ac, H2AK119Ub, and cleaved H3T22 were correlated with each other in all 11 immune cell types (Fig. 4A, Fig. S3A). AM2 consisted of 10 moderately correlated HPTMs of which $\mathrm{H} 3.3 \mathrm{~S} 31 \mathrm{ph}$ and $\mathrm{H} 3 \mathrm{~K} 9 \mathrm{ac}$ had the highest $\mathrm{BC}$ values in the AM2 module (Fig. 4B, Fig. S3B). H4K5ac, H3K9ac and H3.3S31ph were part of both AM1 and AM2. Therefore, these 3 HPTMs were correlated with the highest number of other HPTMs in AM1 and AM2. Interestingly, phosphorylation of H3.3S31 amplifies stimulation-induced transcription, whereas acetylation of $\mathrm{H} 3 \mathrm{~K} 9$ and $\mathrm{H} 4 \mathrm{~K} 5$ mediate cellular shift from transcriptional initiation to elongation ${ }^{16,17}$. Thus, our data suggest AM1 and AM2 are strongly associated with transcription regulation.

Given highly reproducible pairwise HPTMs correlations across all independent cohorts, we calculated an average correlation of all HPTM pairs for each immune cell type (Fig. S1B-C), stratified the average correlations as strong $(|R| \geq 0.6)$, moderate $(0.4 \leq|R|<0.6)$, weak $(0.15 \leq|\mathrm{R}|<0.4)$, or no correlation $(|\mathrm{R}|<0.15)$, and determined the epigenetic modules in each immune cell type (Fig. 1G, Fig. 2G, Methods). Hierarchical clustering using the average pairwise HPTMs correlations (Methods) identified five and four distinct modules in methylation and acetylation panels, respectively, and recapitulated the known hematopoietic differentiation hierarchy in both EpiTOF panels, demonstrating HPCs, myeloid, and lymphoid lineages have distinct correlation networks of HPTMs (Fig. 1G, Fig. 2G). We assessed the number of connections $(\mathrm{N})$ and betweenness centrality (BC) of the HPTMs within individual modules for each cell type to identify important HPTMs (Methods). Betweenness centrality indicates the number of the shortest paths passing through the graph node, i.e., an HPTM, and indicates which node is central to the network.

Conserved HPTM correlation modules across immune cells

Although AM3 was present in all immune cell types, lymphoid cells had moderate, whereas myeloid cells had weak correlations between 16 HPTMs (Fig. 4C, Fig. S3C). H3K14ac had the highest number of connections, whereas $\mathrm{H} 3 \mathrm{~K} 18 \mathrm{ac}$ had the highest $\mathrm{BC}$ value. Both HPTMs are found in transcription start regions of poised and actively transcribed genes ${ }^{18}$, suggesting AM3 is associated with the start of the transcription. Furthermore, since proteolytic cleavage of $\mathrm{H} 3$ tails at T22 is involved in gene regulation and physically removes $\mathrm{K} 14$ and $\mathrm{K} 18^{19}$, positive correlations between cleavedH3T22 and $\mathrm{H} 3 \mathrm{~K} 14 \mathrm{ac}$ or H3K18ac suggest increased acetylations at K14 and K18 occur at untruncated $\mathrm{H} 3$ tails, however simultaneously to $\mathrm{H} 3$ tail cleavage.

Collectively, presence of the three acetylation (AM1, AM2, and AM3) and two methylation (MM1 and MM2) modules across different immune cells in healthy individuals, irrespective of age and geographic location, suggests their universal importance in immune cells.

HPTM correlation modules specific to differentiated immune cells

Methylation module 1 (MM1) and 2 (MM2) (Fig. 3A-B, Fig. In contrast to the conserved methylation and acetylation modules 
bioRxiv preprint doi: https://doi.org/10.1101/2022.01.21.477300; this version posted January 23, 2022. The copyright holder for this preprint (which was not certified by peer review) is the author/funder. All rights reserved. No reuse allowed without permission.

\section{bioR Xiv}

THE PREPRINT SERVER FOR BIOLOGY

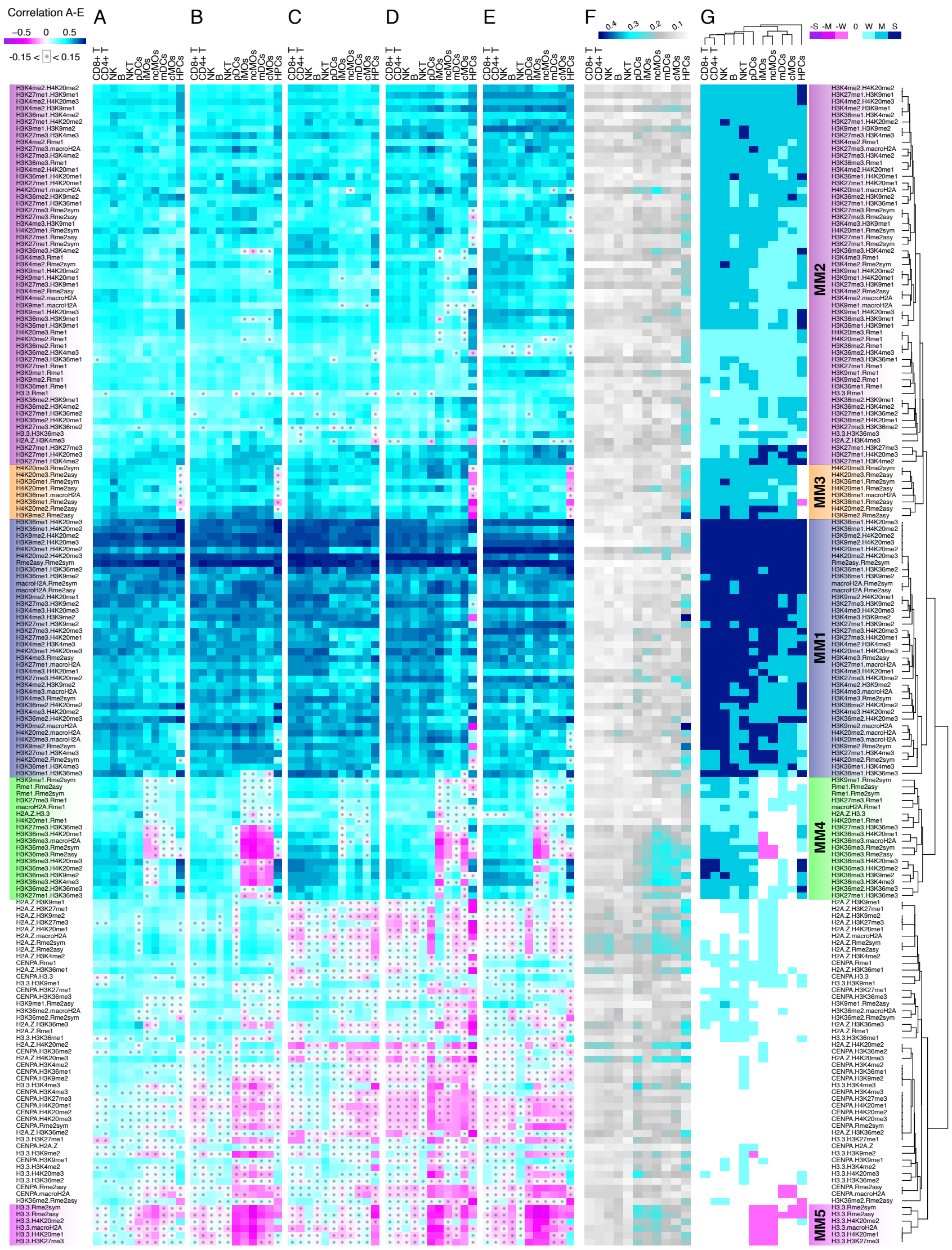

Figure 1. Correlation analysis of the methylation panel shows a high degree of epigenetic conservation across immune cells between independent cohorts.

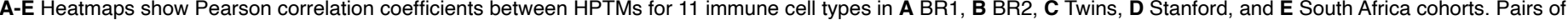

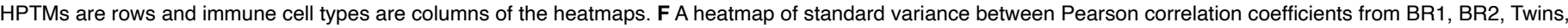
Stanford, and South Africa cohorts. Higher variance indicates increased heterogeneity. G A heatmap of averaged and stratified Pearson correlation coefficients between HPTMs for 11 immune cell types showing five methylation modules. 
bioRxiv preprint doi: https://doi.org/10.1101/2022.01.21.477300; this version posted January 23, 2022. The copyright holder for this preprint (which was not certified by peer review) is the author/funder. All rights reserved. No reuse allowed without permission.

\section{bioR Xiv}

THE PREPRINT SERVER FOR BIOLOGY

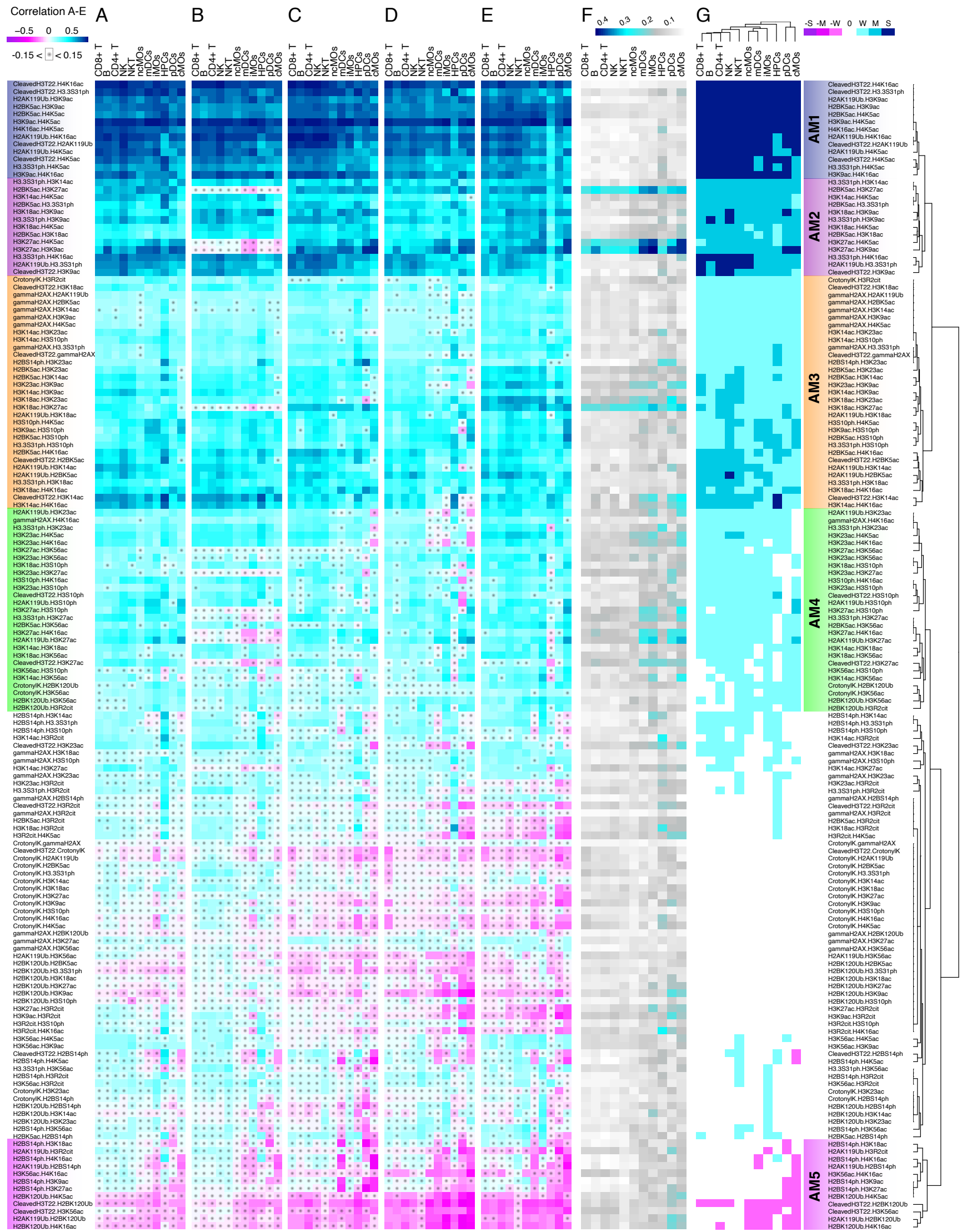

Figure 2. Correlation analysis of the acetylation panel shows a high degree of epigenetic conservation across immune cells between independent cohorts.

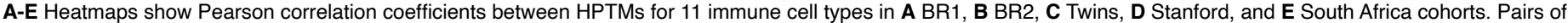

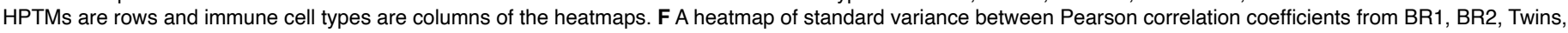

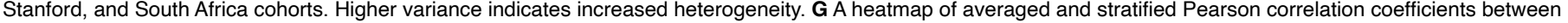
HPTMs for 11 immune cell types showing five acetylation modules. 
bioRxiv preprint doi: https://doi.org/10.1101/2022.01.21.477300; this version posted January 23, 2022. The copyright holder for this preprint (which was not certified by peer review) is the author/funder. All rights reserved. No reuse allowed without permission.

bioRxiv

HPCs
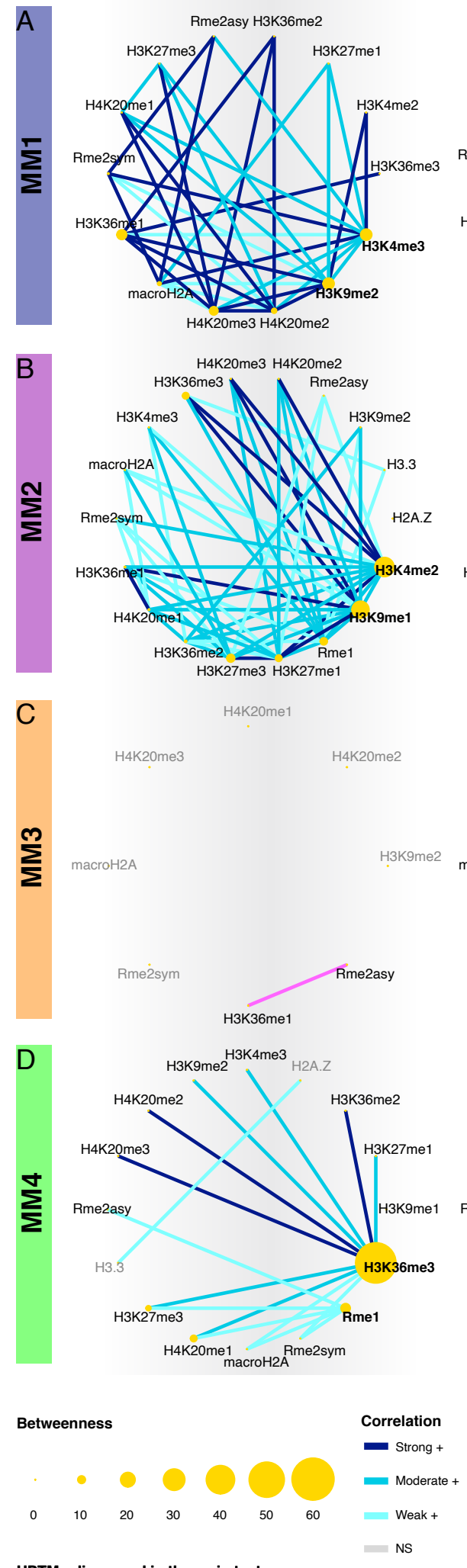

HPTM - discussed in the main text

HPTM - not connectred to the graph of the module
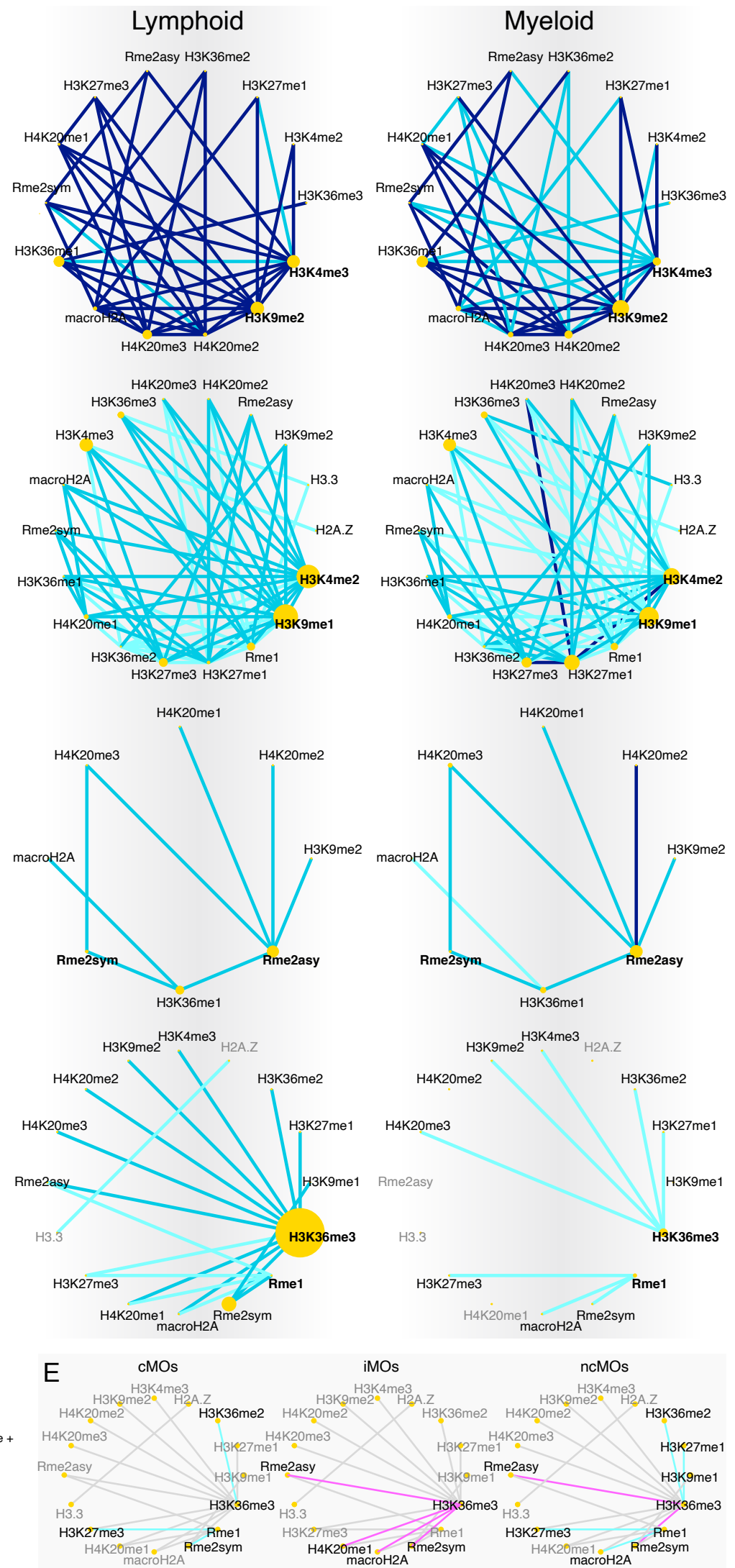

Figure 3. Histone methylation modules in HPCs, average lymphoid and average myeloid cells.

A-B Graph renderings show A methylation module 1 and $\mathbf{B}$ methylation module 2 that were present in all immune cell types. $\mathbf{C}$ Methylation module 3 was present in

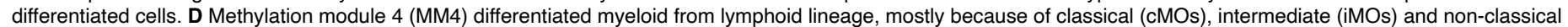

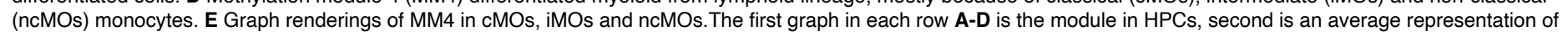

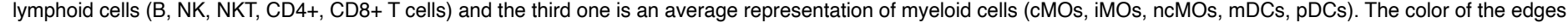
represents stratified correlation coefficients. 
bioRxiv preprint doi: https://doi.org/10.1101/2022.01.21.477300; this version posted January 23, 2022. The copyright holder for this preprint (which was not certified by peer review) is the author/funder. All rights reserved. No reuse allowed without permission.

\section{bioR Xiv}

HPCs
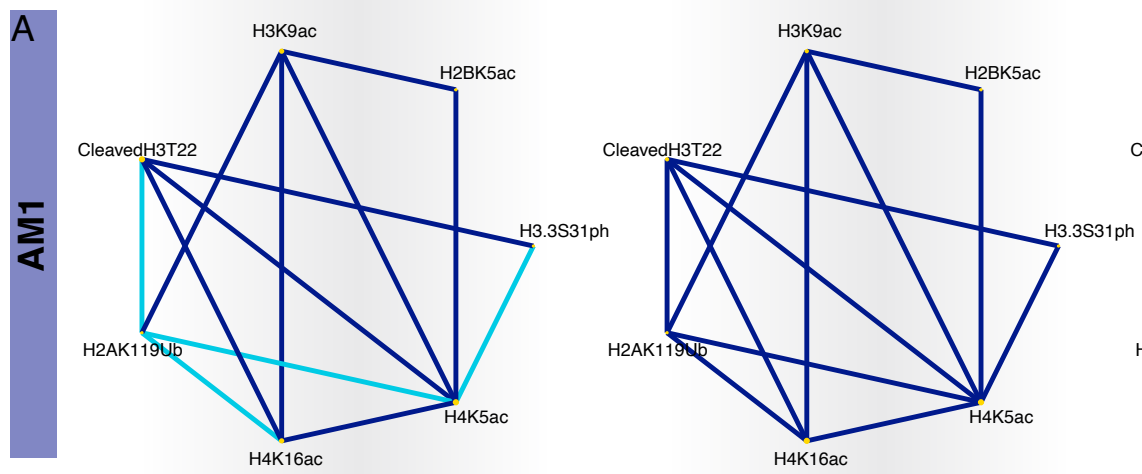

Lymphoid

\section{ARTICLE PREPRINT}

THE PREPRINT SERVER FOR BIOLOGY
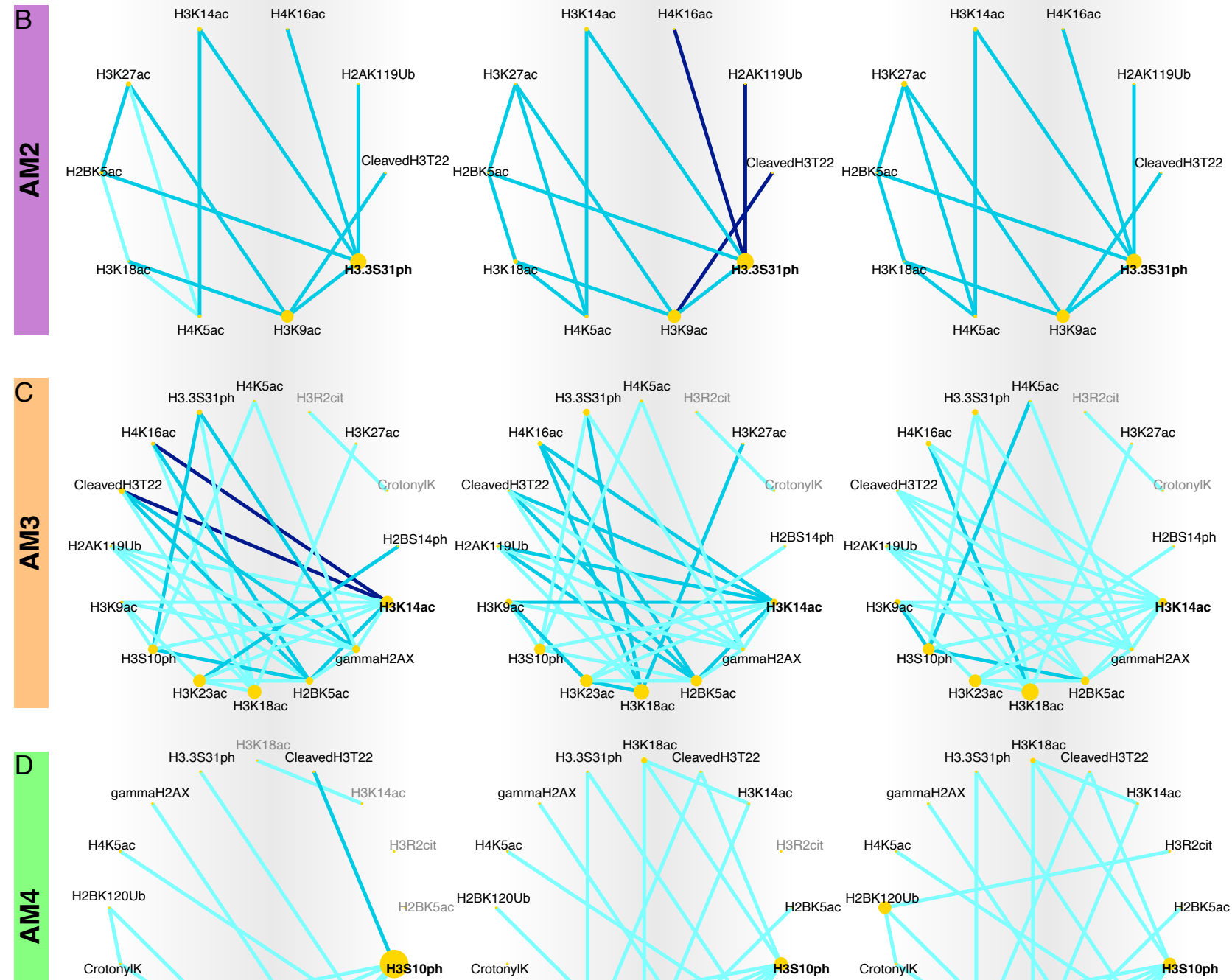

H3.3S31ph ${ }^{\mathrm{H} 3 \mathrm{~K} 18 \mathrm{ac}}$ CleavedH3T22

$$
\text { H3.3S31ph }{ }^{\text {H3K18ac }} \text { CleavedH3T22 }
$$
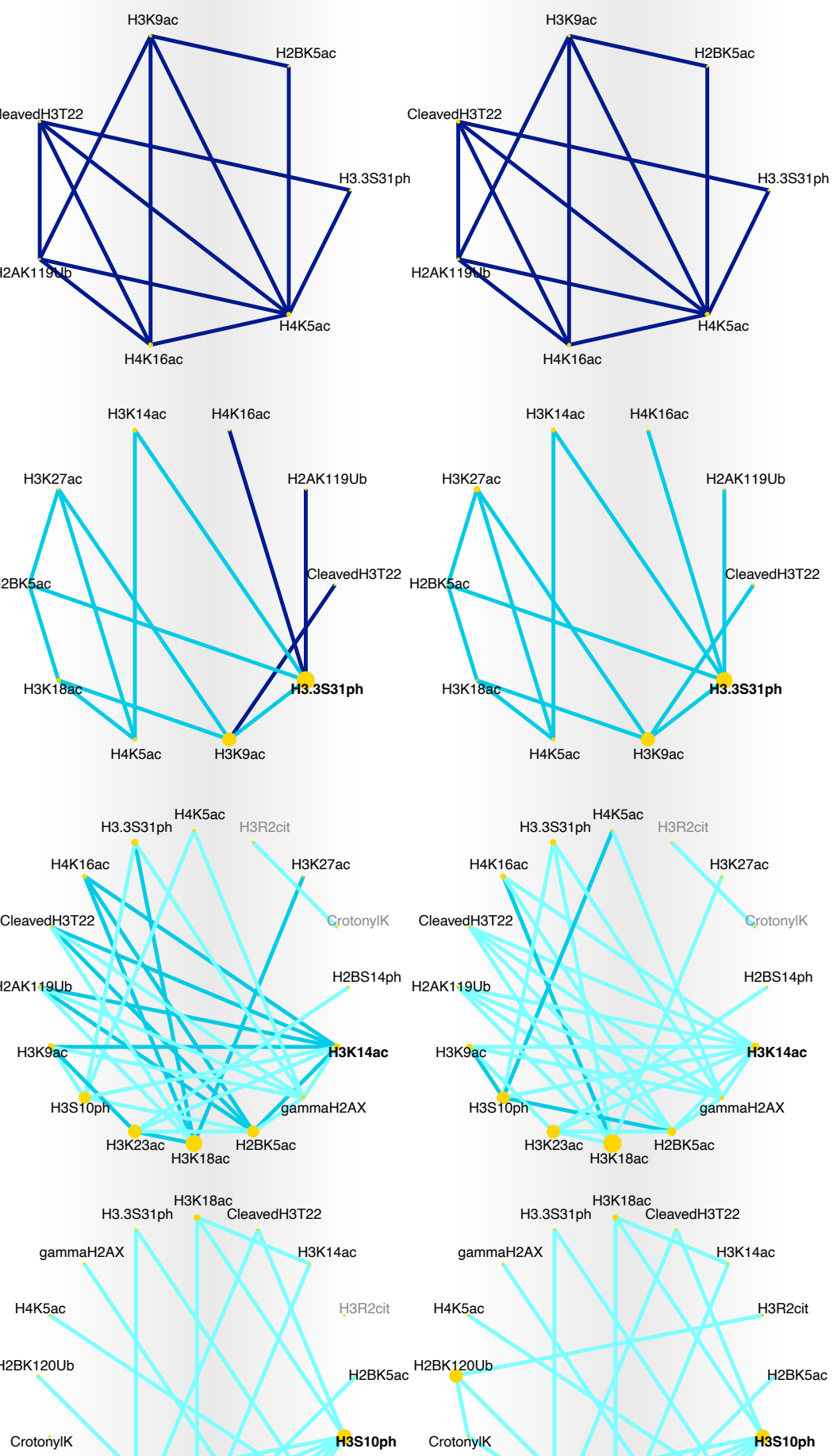

Myeloid 


\section{bioR Xiv \\ THE PREPRINT SERVER FOR BIOLOGY}

across all immune cell types, MM3 was present in differentiated immune cells, but not in HPCs (Fig. 3C). MM3 included Rme2asy, H3K36me1, Rme2sym, macroH2A, H4K20me1, H4K20me2, $\mathrm{H} 4 \mathrm{~K} 20 \mathrm{me} 3$, and $\mathrm{H} 3 \mathrm{~K} 9 \mathrm{me} 2$ with moderate or strong correlations between them in lymphoid and myeloid cells (Fig. 3C, Fig. S2C). Rme2asy had the highest $\mathrm{BC}$ value across all differentiated immune cell types (Fig. 3C). The stark difference between HPCs and the differentiated immune cells suggests the presence of MM3 is a hallmark of the differentiated cellular state.

Similarly, only a part of AM4 was present in HPCs (Fig. 4D, Fig. S3D). This module was characterized by a shift in the highest $\mathrm{BC}$ value from $\mathrm{H} 3 \mathrm{~S} 10 \mathrm{ph}$ in HPCs to $\mathrm{H} 3 \mathrm{~K} 56 \mathrm{ac}$ in lymphoid and myeloid cells. The shift was associated with an increase in the number of weak correlations for $\mathrm{H} 3 \mathrm{~S} 10 \mathrm{ph}, \mathrm{H} 3 \mathrm{~K} 56 \mathrm{ac}$, and $\mathrm{H} 3 \mathrm{~K} 27 \mathrm{ac}$ with other HPTMs in lymphoid and myeloid cells. H3K56ac destabilizes the DNA-nucleosome structure and enables unwrapping of the DNA; thus, increasing the binding affinity of the chromatin remodeling proteins that regulate transcription ${ }^{20}$. H3S10ph, among its many functions, regulates transcription by several mechanisms ${ }^{21}$. Together, our results suggest AM4 is associated with establishment of open chromatin and transcription elongation preferentially in differentiated immune cells in blood.

\section{Lineage-specific HPTM correlation modules}

Two methylation modules, MM4 and MM5, were different in myeloid cells compared to HPCs and lymphoid cells. MM4 was present in HPCs and lymphoid cells, but not in all myeloid cells (Fig. 3D, Fig. S2D), whereas MM5 was exclusively present in a subset of myeloid cells, centered around H3.3 (Fig. 1G). In MM4, H3K36me3 was correlated with the highest number of HPTMs and had the highest BC value in HPCs and lymphoid cells. While H3K36me3 was positively correlated with Rme2sym, macroH2A, H4K20me1, H3K27me3, and Rme2asy in HPCs and lymphoid cells, it had inverse or no correlation with the same HPTMs in cMOs, iMOs and ncMOs (Fig. 3E). The negative correlations were driven by the increase in proportions of cMOs, iMOs and ncMOs with higher levels of macroH2 A and $\mathrm{H} 3 \mathrm{~K} 36 \mathrm{me} 3$, rather than the overall increase in abundance of these HPTMs (Fig. S4). H3K36me3 marks bodies of recently transcribed genes ${ }^{22}$; thus, our results are in line with transcriptional activity of monocytes during differentiation into ncMOs in blood ${ }^{23}$. In contrast, conserved correlations between H3K36me3 and other HPTMs in MM4 in HPCs and lymphoid cells indicate their low level of transcriptional activity in homeostasis. Collectively, our results identified a putative role of H3K36me 3 in regulation of transcription during immune cell differentiation.

Module MM5 consisted of negative correlations between H3.3 and H3K27me3, Rme2sym, Rme2asy, macroH2A, H4K20me1, and H4K20me2 in pDCs, iMOs, and ncMOs (Fig. 1G), which is in line with previously described decrease of heterochromatin HPTMs, such as $\mathrm{H} 3 \mathrm{~K} 27 \mathrm{me} 3$ and macroH2A, with the incorporation of H3.3 into chromatin ${ }^{24}$. H3.3 is enriched in regions of transcribed genes, enhancers, and regulatory elements ${ }^{25}$. Increased proportions of pDCs, iMOs, and ncMOs incorporated H3.3 into chromatin simultaneously increasing $\mathrm{H} 3 \mathrm{~K} 36 \mathrm{me} 3$ and removing arginine methylations (Rme2sym, Rme2asy), macroH2A (Fig. S5), H4K20me1, H4K20me2, and H3K27me3 (data not shown).

\section{ARTICLE PREPRINT}

MM4 and MM5 demonstrated higher variability in correlations with several HPTMs in myeloid cells. To our knowledge, these modules are the first evidence of dynamic relationships between global arginine methylations (Rme2sym, Rme2asy), H4K20me1 and H4K20me2, and H3K36me3 or H3.3, collectively suggesting during active transcription arginine dimethylations need to be removed.

Overall, our analysis of pairwise HPTM correlation network analysis found highly conserved histone methylations and acetylations modules that fall into three categories: (1) modules conserved across all immune cell types with varying strength of correlations (MM1, MM2, AM1, AM2, and AM3), (2) modules specific to lymphoid (MM4) or myeloid lineage (MM5), and (3) modules specific to differentiated immune cell types but absent or less connected in HPCs (MM3, AM4).

Peripheral blood hematopoietic progenitors reveal high epigenetic heterogeneity and histone modifications associated with bona fide hematopoietic stem cells phenotype

We sought to investigate the extent of epigenetic diversity in an unbiased manner by clustering immune cells using only HPTMs with Phenograph ${ }^{26}$ (Methods). When using the methylation panel, we identified 12 cell clusters (Fig. 5A), which included (i) 5 methylation clusters (MC1, MC3, MC4, MC5, and MC10) with low abundances of HPTMs, (ii) 1 methylation cluster (MC6) with high abundances of all but 2 HPTMs, (iii) 4 methylation clusters (MC2, MC7, MC8, and MC9) with moderate-to-high abundances of most HPTMs, and (iv) 2 clusters with mixed abundances of HPTMs (MC11 and MC12). As expected from the correlation analysis in which methylation modules MM1, MM2, and MM3 were conserved in all immune cell types (Fig. 1), we found each cluster contained every immune cell type (Fig. 5B). Despite the conserved methylation modules, we also observed several lineagespecific clusters. For instance, myeloid cells (cMOs, iMOs, ncMOs, mDCs, and pDCs) dominated clusters MC3, MC5, MC7, and MC8 (>75\%), whereas lymphoid cells (B, T, NK, and NKT cells) dominated clusters $\mathrm{MC} 1, \mathrm{MC} 2, \mathrm{MC} 4$, and $\mathrm{MC} 10(>80 \%)$. We also observed clusters dominated by one or two cell types. For instance, cMOs accounted for $>50 \%$ of MC8, whereas HPCs and pDCs accounted for $>75 \%$ of MC9 (Fig. 5B). MC6 was enriched in HPCs (37.5\%), which was marked by higher abundances of H3K9me2, and three methylation states (me1, me2 and me3) of H3K36 and H4K20 (Fig. 5A). Notably, higher abundances of these methylation marks in MC6 were solely driven by the HPCs (Fig. 5C-D, Fig. S5). In fact, average abundance of $\mathrm{H} 3 \mathrm{~K} 9 \mathrm{me} 2, \mathrm{H} 3 \mathrm{~K} 36$ and $\mathrm{H} 4 \mathrm{~K} 20$ methylations in $87 \%$ of HPCs in MC6 (6.9\% of all HPCs) was 2 -fold higher that their abundances in the other more differentiated immune cells (Fig. 5E, Fig. S6). Finally, CD $34^{\mathrm{dim}} \mathrm{CD} 45^{\mathrm{dim}}$ HPCs separated into two subsets $\mathrm{H} 3 \mathrm{~K} 36 \mathrm{me}^{+} \mathrm{HPCs}$ ( $6.9 \%$ of total HPCs) and H3K36me1- HPCs ( $2 \%$ of total HPCs), though H3K9me2 was elevated in both subsets (Fig. 5E).

Similarly, using the acetylation panel, we identified 12 cell clusters of which 8 acetylation clusters (AC2, AC3, AC6, AC7, AC9, AC10, $\mathrm{AC} 11$ and $\mathrm{AC} 12)$ had low to moderate abundances of HPTMs, whereas 4 acetylation clusters (AC1, AC4, AC5, and AC8) had moderate to high abundances of HPTMs (Fig. 5F). Overall, 
bioRxiv preprint doi: https://doi.org/10.1101/2022.01.21.477300; this version posted January 23, 2022. The copyright holder for this preprint (which was not certified by peer review) is the author/funder. All rights reserved. No reuse allowed without permission.

\section{bioR Xiv}

\section{ARTICLE PREPRINT}

THE PREPRINT SERVER FOR BIOLOGY

A

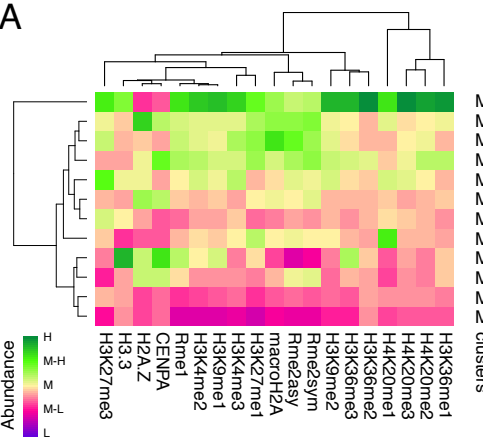

B

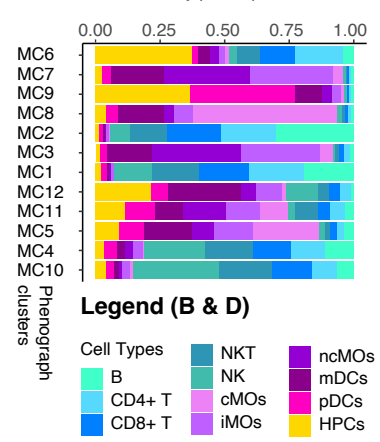

E
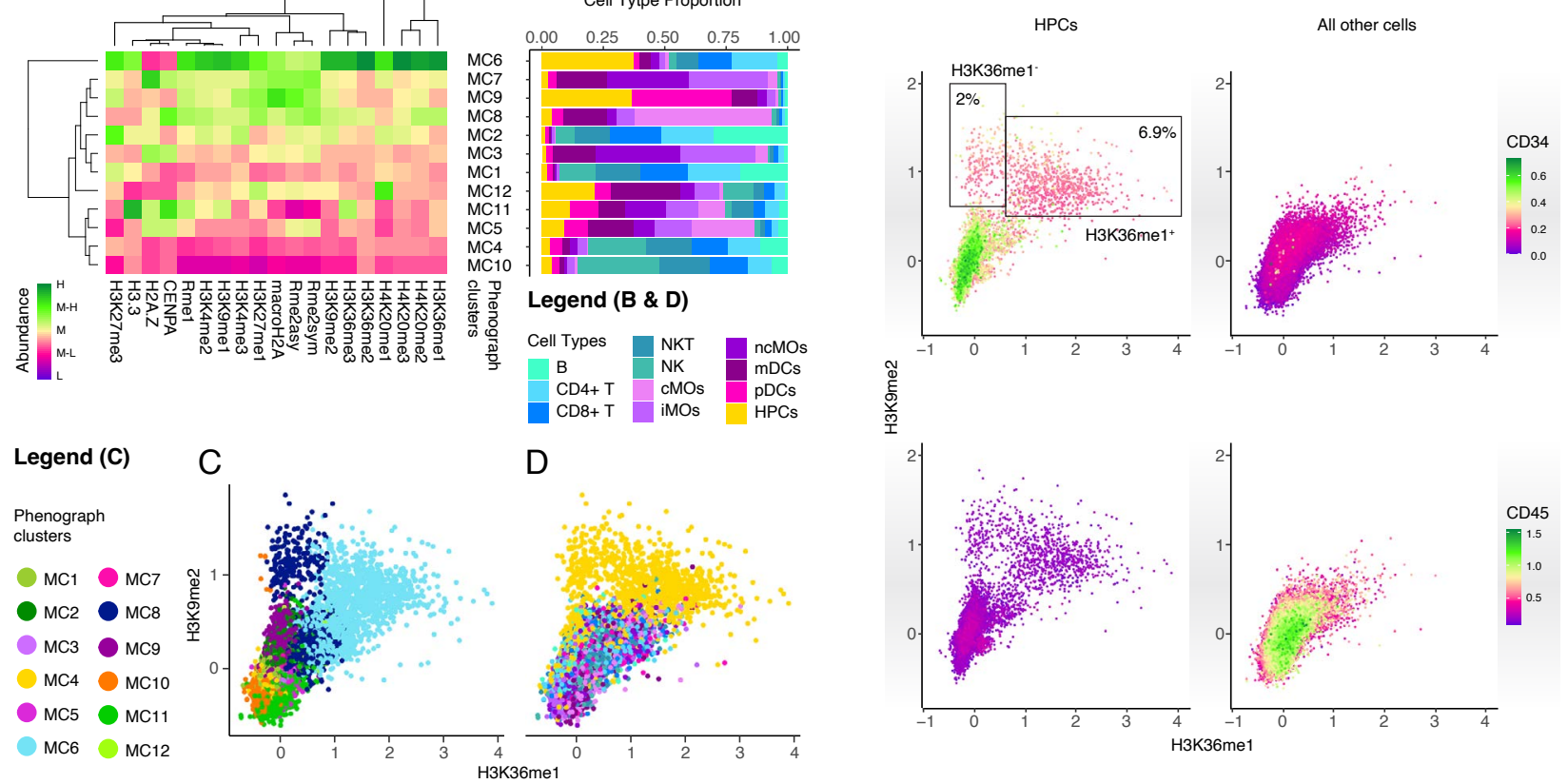

$\mathrm{F}$

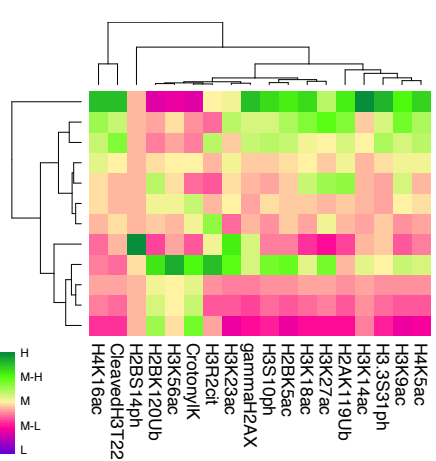

G Cell Type Proportion

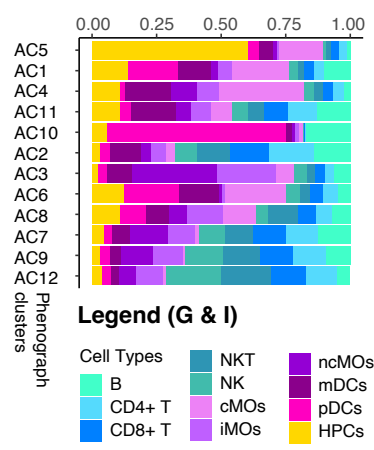

Legend (H)
Phenograph
clusters
AC1 $A C 7$
$A C 2$
$A C 8$

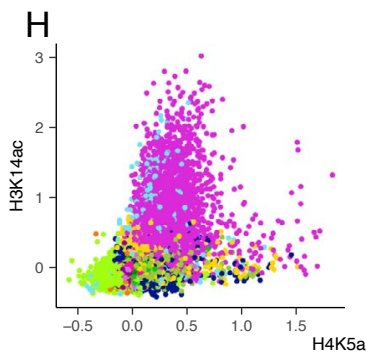

I

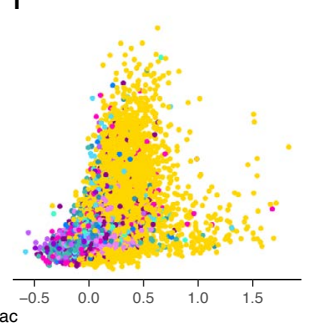

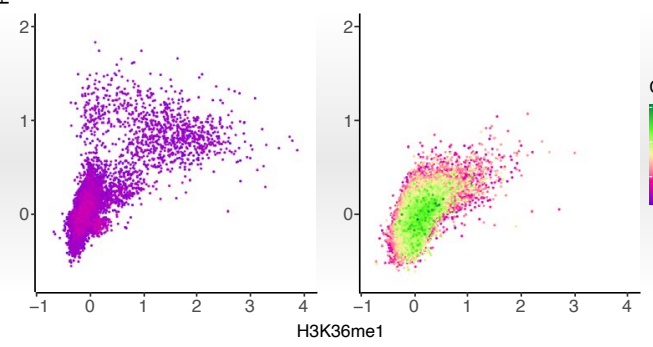

J

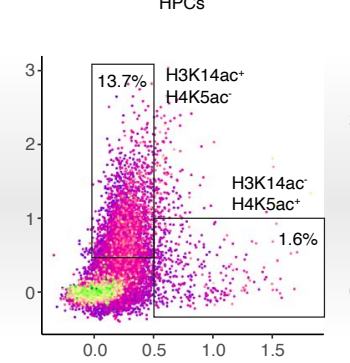

All other cells

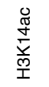

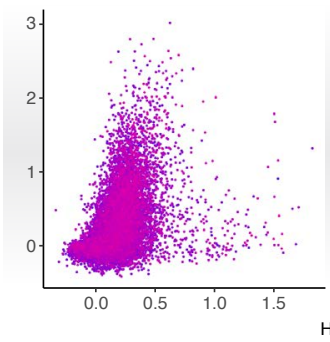

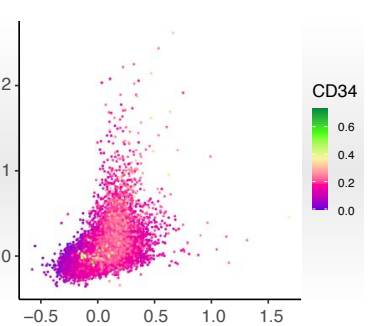

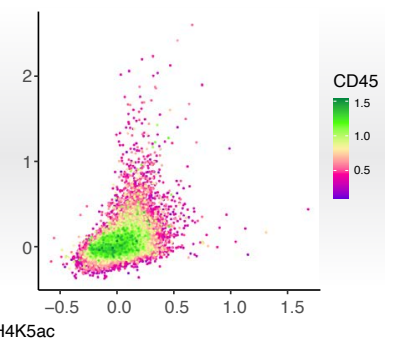

Figure 5. Clustering analysis of methylation and acetylation panels points to increased heterogeneity in hematopoietic cells and reveals distinct patterns of HPTMs.

A A heatmap showing cell methylation clusters (MC) and average abundances of HPTMs in the methylation panel. Abundance of HPTM is defined in ranges of low (L), moderately low $(M-L)$, moderate $(M)$, moderately high $(M-H)$ and high $(H)$.

B Proportion of immune cell types in each of the MC clusters.

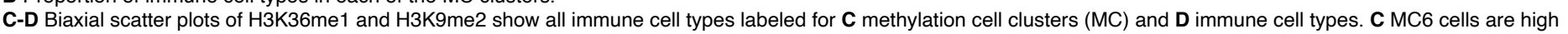

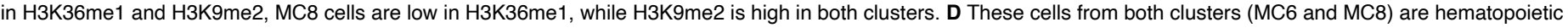
progenitors (HPCs).

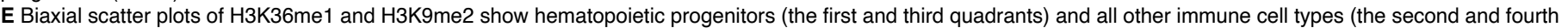

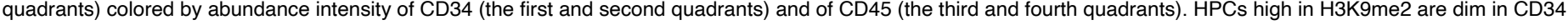
and CD45 resembling phenotypes of bona fide hematopoietic stem cells.

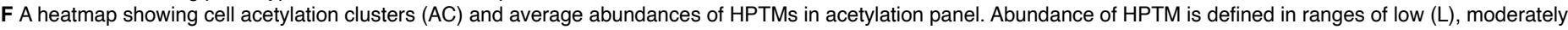
low $(M-L)$, moderate $(M)$, moderately high $(M-H)$ and high $(H)$.

G Proportion of immune cell types in each of the AC clusters.

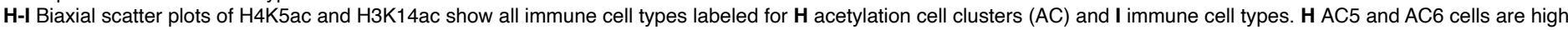

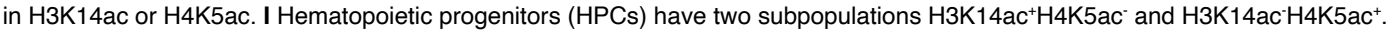

$\mathrm{J}$ Biaxial scatter plots of $\mathrm{H} 4 \mathrm{~K} 5 \mathrm{ac}$ and $\mathrm{H} 3 \mathrm{~K} 14 \mathrm{ac}$ show hematopoietic progenitors (the first and third quadrants) and all other immune cell types (the second and fourth

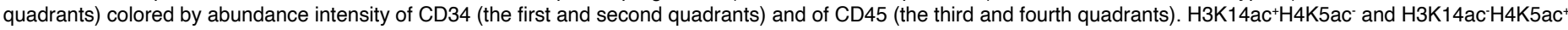
HPCs are dim in CD34 and CD45 resembling phenotypes of bona fide hematopoietic stem cells. 


\section{bioR Xiv}

THE PREPRINT SERVER FOR BIOLOGY

we found a mutually exclusive epigenetic pattern shared by all immune cell types. Cell clusters (e.g., AC1, AC4, AC5) with high H4K5ac, H3K9ac, H3.3S31 ph, H3K14ac, H2AK119Ub, H3K27ac, H3K18ac, H2BK5ac, H3S10ph, cleaved H3T22, and H4K16ac had low-to-moderately low H3R2cit, lysine crotonylation (crotonylK), $\mathrm{H} 3 \mathrm{~K} 56 \mathrm{ac}, \mathrm{H} 2 \mathrm{BK} 120 \mathrm{Ub}$, and H2BS14ph. In contrast, cell clusters with higher H3R2cit, H3K56ac, H2BK120Ub, H2BS14ph and crotonylK (e.g., AC7, AC9, AC12) had lower abundances of the other HPTMs (Fig. 5F). All acetylation clusters contained every immune cell type, but we also found cell type-specific clusters. For instance, HPCs and pDCs accounted for more than $60 \%$ in cluster AC5 and AC10, respectively (Fig. 5G). Further, we found higher abundances of HPTMs in AC5 were driven by HPCs and pDCs (Fig. S7). Finally, we observed two mutually exclusive subpopulations of peripheral blood CD34 ${ }^{+}$HPCs in AC5 (Fig. 5H-I) that were either $\mathrm{H} 3 \mathrm{~K} 14 \mathrm{ac}^{+} \mathrm{H} 4 \mathrm{~K}^{2} \mathrm{ac}^{-}(13.7 \%$ of total $\mathrm{HPCs})$ or $\mathrm{H} 3 \mathrm{~K} 14 \mathrm{ac}^{-}$ $\mathrm{H} 4 \mathrm{~K} 5 \mathrm{ac}^{+} \mathrm{HPCs}$ ( $1.6 \%$ of total HPCs). Comparable to the HPCs in methylation panel, the HPCs in AC5 were CD34 ${ }^{\text {dim }} \mathrm{CD} 45^{\mathrm{dim}}$ (Fig. 5J), probably representing bona fide hematopoietic stem cells.

Across both EpiTOF panels, we identified clusters dominated by HPCs, suggesting higher epigenetic heterogeneity in HPCs, in line with the correlation analyses.

\section{Lymphoid and myeloid cells follow distinct epigenetic trajectories}

Presence of every immune cell type in all clusters defined using HPTMs suggests each immune cell type exists on a continuum. Because histones are post-translationally modified in a coordinated manner in response to stimuli, trajectory inference analysis can identify these coordinated modifications along a continuum. To date, no cellular trajectories using HPTMs have been described.

We used tSpace, a trajectory inference algorithm to define epigenetic trajectories of immune cells (Methods, Fig. S7A-B) ${ }^{27}$. When using the methylation panel, tSpace identified a circular trajectory (Fig. 6A). We arbitrarily defined the origin of the circular trajectory as the region with the highest proportion of HPCs, which corresponded to the methylation cell cluster MC6, characterized by higher abundances of methylation at H3K9, H3K36, and H4K20 (Fig. 6B). Using the origin as a reference, we identified two segments in the circular trajectory that converged on the opposite side. The upper and lower segments were enriched in myeloid and lymphoid cells, respectively (Fig. 6A, Fig. S8C). The myeloid segment was characterized by high abundances of all but one histone methylation, $\mathrm{H} 3 \mathrm{~K} 27 \mathrm{me} 3$, which was higher in the lymphoid segment (Fig. 6C). H3K27me3 is a repressive HPTM that enables formation of heterochromatin, therefore suggesting lymphocytes have globally more compact chromatin regions and possibly smaller transcriptional gene repertoire than myeloid cells. However, colocalization of H3K27me 3 and H3K4me3 within the promoter regions marks bivalent promoters poised for rapid expression after $\mathrm{H} 3 \mathrm{~K} 27 \mathrm{me} 3$ removal $^{28}$. Interestingly, H3K4me2 and $\mathrm{H} 3 \mathrm{~K} 4 \mathrm{me} 3$ were present in high abundance in the lymphoid, but not the myeloid segment (Fig. 6C), suggesting the presence of bivalent promoters that allow lymphocytes to circulate blood with minimal gene expression and rapidly increase expression of genes when antigens are detected ${ }^{29-31}$. Collectively, our results are

\section{ARTICLE PREPRINT}

in line with previous studies showing that lymphocytes have higher heterochromatin, small nuclei, and a reduced transcriptional rate compared to myeloid cells $\mathrm{s}^{32,33}$.

\section{Reduced histone methylations are associated with memory and longer cell lifespan}

We found NK cells were divided into two populations along the methylation trajectory. A population of $\mathrm{CD} 56^{\text {bright }} \mathrm{CD} 16^{\mathrm{dim}} \mathrm{NK}$ cells localized along the myeloid segment and $\mathrm{CD} 56^{\text {dim }} \mathrm{CD} 16^{\text {bright }}$ NK cells localized along the lymphoid segment (Fig. 6D-E). $\mathrm{CD} 56^{\text {bright }} \mathrm{CD} 16^{\text {dim }} \mathrm{NK}$ cells had increased histone methylations in comparison to $\mathrm{CD} 56^{\text {dim }} \mathrm{CD} 16^{\text {bright }}($ Fig. $\mathbf{6 F})$. CD56 $6^{\text {bright }} \mathrm{CD} 16^{\text {dim }} \mathrm{NK}$ cells are cytokine producers with immunoregulatory properties, whereas $\mathrm{CD} 56^{\mathrm{dim}} \mathrm{CD} 16^{\text {bright }} \mathrm{NK}$ cells exhibit cytotoxic activity and immune memory ${ }^{34-38}$. Separation of functionally distinct NK cell subtypes into two trajectory segments (myeloid and lymphoid) suggests that in addition to distinguishing by lineage, histone methylations may also distinguish metabolically high and low states corresponding to cytokine producing $\left(\mathrm{CD} 56^{\text {bright }} \mathrm{CD} 16^{\mathrm{dim}}\right)$ and dormant memory NK cells (CD56 $\left.{ }^{\text {dim }} \mathrm{CD} 16^{\text {bright }}\right)$, respectively. Indeed, memory $\mathrm{CD} 56^{\mathrm{dim}} \mathrm{CD} 16^{\text {bright }} \mathrm{NK}$ cells shared methylation trajectory with other memory immune cell types ( $T$ and $B$ lymphocytes, Fig. 6D, Fig. S8C) and have a longer lifespan than cells without memory (cytokine producing NK cells and myeloid

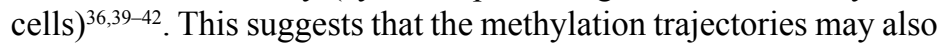
be associated with memory and cell lifespan.

We further investigated whether higher histone methylations are associated with cell lifespan. All cellular methylation reactions, including histone modifications, are dependent on S-adenosylmethionine (SAM) as the methyl donor ${ }^{43}$. SAM is replenished in cells through one-carbon metabolism consisting of the folate and methionine cycles (Fig. 6G) $)^{44}$. Restriction of folate and methionine cycles has been shown to extend cell lifespan ${ }^{45,46}$. Briefly, folate receptor 2 (FOLR2), solute carrier family 19 member 1 (SLC19A1), and SLC46A1 transport dietary folate into cells. In folate cycle, methylenetetrahydrofolate reductase (MTHFR) converts 5,10-methylenetetrahydrofolate (5-10-MTHF) into 5-methyltetrahydrofolate (5-MTHF), supporting the synthesis of SAM through a reaction catalyzed by 5-methyltetrahydrofolatehomocysteine methyltransferase $(M T R)^{44}$. In the methionine cycle, adenosylhomocysteinase $(A H C Y)$ converts S-adenosyl-Lhomocysteine (SAH) into homocysteine, which is a precursor of SAM (Fig. 6G). Both are unidirectional biochemical reactions in the folate and methionine cycles.

Myeloid cells had substantially higher net sum of all methylations than lymphoid cells (Fig. 6H; Methods). Therefore, we hypothesized that one-carbon metabolism is increased in myeloid cells. To test this hypothesis, we examined the expression of folate receptors, transporters, and genes encoding for enzymes involved in folate or methionine cycles using The Human Blood Atlas (Methods $)^{47}$. Classical, intermediate, and non-classical monocytes had higher expression of receptors (FOLR2, SLC19A1, SLC46A1) and two enzymes (AHCY, MTHFR) compared to lymphoid cells, suggesting lymphoid cells may have reduced active uptake of dietary folate and reduced synthesis of SAM (Fig. 6I $)^{48}$. These results suggest most lymphoid cells have restricted folate and 
bioRxiv preprint doi: https://doi.org/10.1101/2022.01.21.477300; this version posted January 23, 2022. The copyright holder for this preprint (which was not certified by peer review) is the author/funder. All rights reserved. No reuse allowed without permission.

\section{bioR Xiv}

THE PREPRINT SERVER FOR BIOLOGY
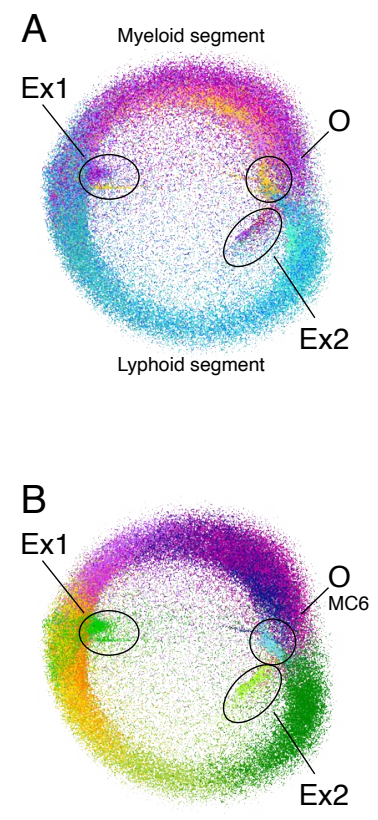

Legend (A)

Cell Types

\begin{tabular}{l|ll} 
B & NKT & ncMos \\
NK & mDCs
\end{tabular}

CD4+ T cMOs $\square$ pDCs

CD8+T iMOs HPCs

Legend (C \& F)

Abundance

$\begin{array}{llllll} & 1 & 1 & & & \\ 0 & 0.2 & 0.4 & 0.6 & 0.8 & 1\end{array}$

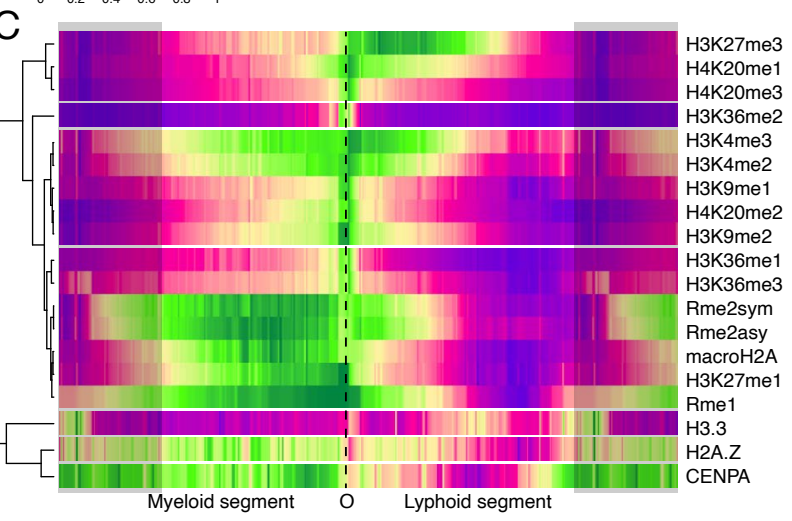

Legend (B)

Phenograph clusters

MC1 MC4 MC7 MC10

$M C 2$ MC5 $M C 8$ MC11

мс3 мс6 мс9 мс12
D

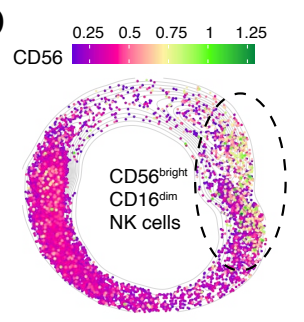

E

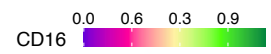

$\mathrm{F}$
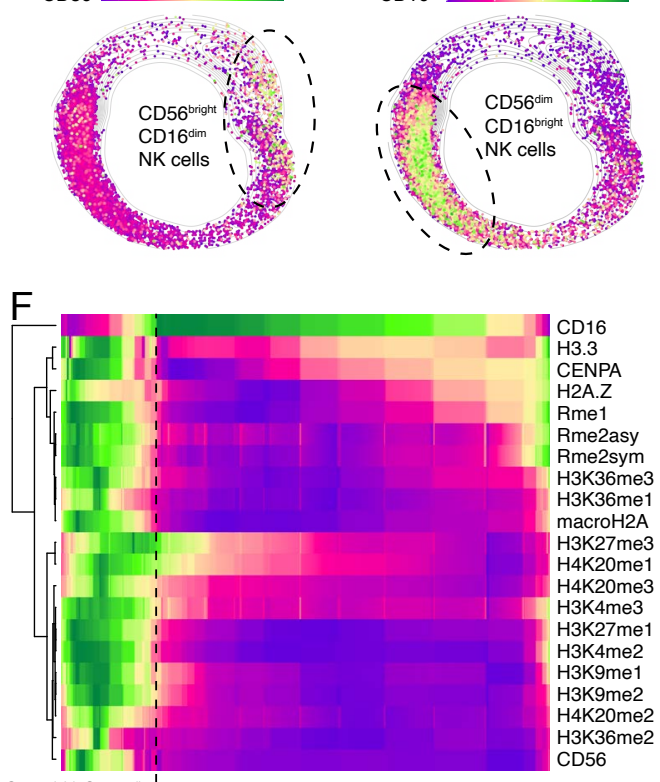

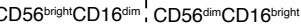
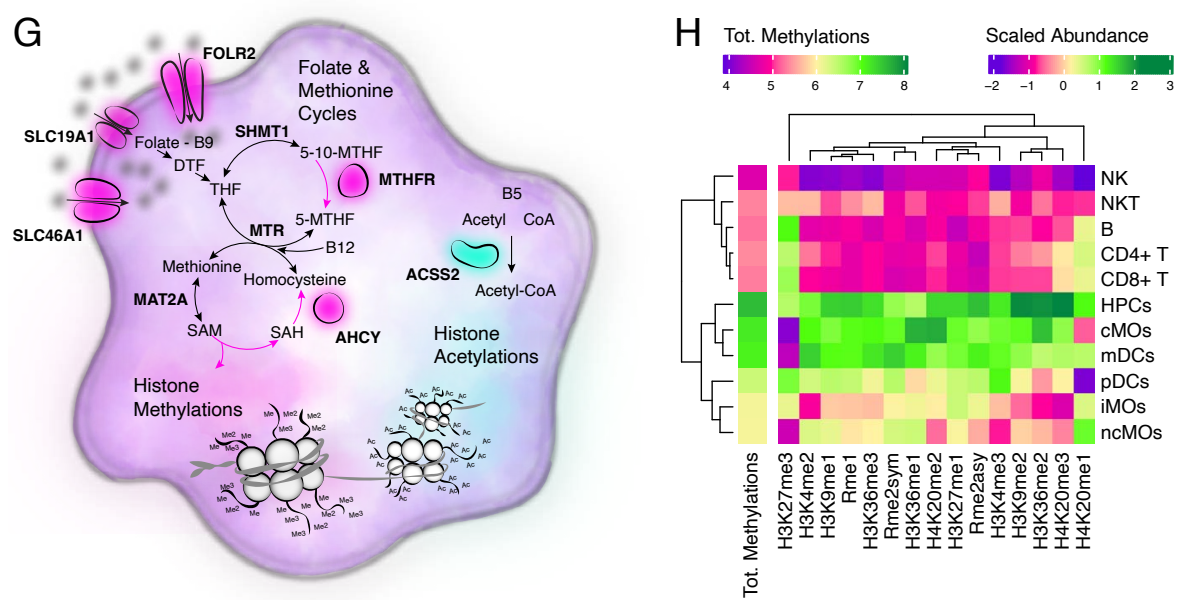
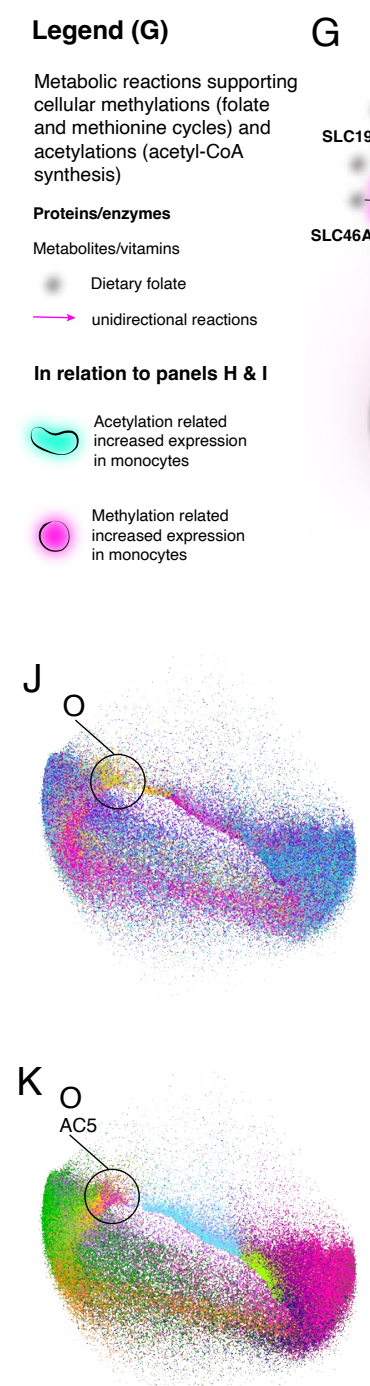

Cell Types

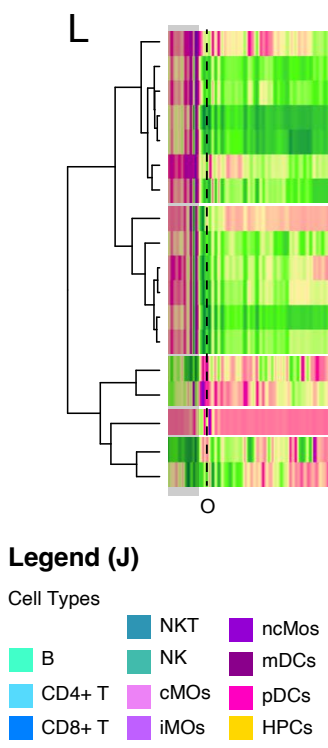

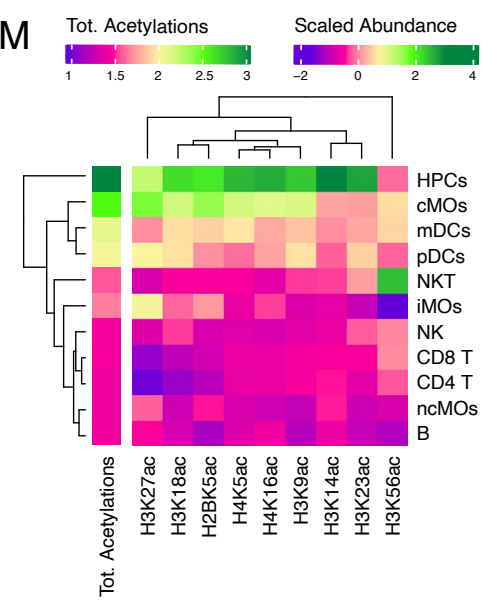

Phenograph clusters

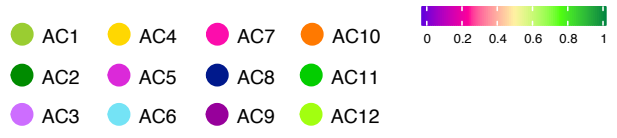

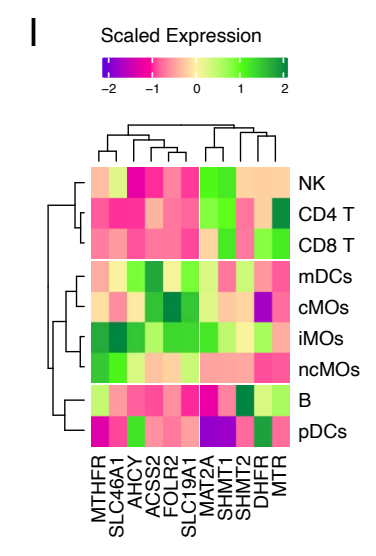


bioRxiv preprint doi: https://doi.org/10.1101/2022.01.21.477300; this version posted January 23, 2022. The copyright holder for this preprint (which was not certified by peer review) is the author/funder. All rights reserved. No reuse allowed without permission.

\section{bioR Xiv \\ THE PREPRINT SERVER FOR BIOLOGY}

ARTICLE PREPRINT

methionine metabolism compared to myeloid cells. Furthermore, largely enriched along the methylation trajectory. lymphoid cells ( $\mathrm{T}, \mathrm{B}$, and $\mathrm{CD} 56^{\text {dim }} \mathrm{CD} 16^{\text {bright }} \mathrm{NK}$ cells) with reduced global histone methylations and low expression of crucial enzymes in folate and methionine cycles, live up to several years and exhibit immune memory, whereas myeloid cells, which exhibit upregulated folate and methionine cycles, live up to 14 days $^{36}$. Our findings are in line with studies showing restriction of folate and methionine metabolism extends lifespan ${ }^{45,46}$, but extending them to demonstrate, for the first time, difference in global histone methylation abundances and one-carbon metabolism between myeloid and lymphoid lineages associated with the length of cellular life span in immune cells.

The highest abundances of H3K36me3 and H4K20me1 are associated with transcriptional activity and differentiation of monocytes

Trajectory analysis also identified two clusters, Ex1 and Ex2 (Fig. 6A-B). Cluster Ex1 was enriched in myeloid cells (especially cMOs, iMOs and ncMOs) and characterized by high abundance of H3K36me3 (Fig. S8D). Cells increase abundance of H3K36me3 within actively transcribed regions after RNA polymerase II transcribed the region to prevent spurious RNA polymerase II transcription initiation from within the gene bodies ${ }^{49}$. Thus, our findings indicate differentiation of monocytes from cMOs to iMOs to ncMOs is accompanied by the increased transcriptional activity, reflecting ongoing monocytic differentiation in blood $^{50}$.

Cluster Ex2, characterized by a high abundance of H4K20me1, was enriched in mDCs, iMOs, ncMOs, and NK cells (Fig. S8E). $\mathrm{H} 4 \mathrm{~K} 20 \mathrm{me} 1$ is associated with active promoters, initiation of transcriptional activation, and tightly regulated by the cell cycle progression with the highest abundance in mitosis and G1 phase ${ }^{51}$. Therefore, mDCs, iMOs, ncMOs, and NK cells in Ex2 cluster may be recently divided cells that exited the mitosis and are in G0/G1 phase. Separation of Ex1 and Ex2 clusters in trajectory inference analysis indicates cells with the highest abundances of H3K36me 3 and H4K20me1 are not abundant in all other HPTMs that were

\section{Increased histone acetylations in myeloid cells are metabolically supported}

A similar trajectory inference analysis of the acetylation panel showed immune cells exist in two mutually exclusive epigenetic states (Fig. 6J-L, Fig. S8B). All immune cells harbor either high abundances of most HPTMs with low abundances of H2BK120Ub, H3K56ac, CrotonylK and H3R2cit, or low abundances of most HPTMs with high abundances of H2BK120Ub, H3K56ac, CrotonylK, and H32Rcit.

However, the net sum of all acetylations for each cell type demonstrated a marked increase in multiple histone acetylation marks in HPCs, mDCs, and cMOs compared to B, T, and NK cells (Fig. 6M, Methods), suggesting myeloid cells exhibit more open chromatin that is permissive to transcription ${ }^{52}$. Moreover, all cellular acetylation reactions depend on acetyl-Coenzyme A (acetyl-CoA) as a substrate, which is synthesized by acetyl-CoA synthetase 2 $(A C S S 2)^{53}$. ACSS2 is expressed at a higher level within the myeloid compartment, specifically in cMOs, mDCs, and iMOs (Fig. 6I). Further, H3K27ac was higher in cMOs, iMOs, HPCs, and pDCs, which marks enhancers and promoters of actively transcribed genes. Its abundance in monocytic cells indicates activation of gene expression associated with differentiation ${ }^{50,54}$. Strikingly, across all immune cell types H3K56ac was the highest in NKT cells (Fig. 6M), which has not been reported before. While H3K56ac has been demonstrated to open chromatin, it is also implicated in DNA damage sensing and response ${ }^{55}$, which stalls DNA replication forks and induce the expression of ligands for the NKG2D receptor found in NK, NKT and CD8+ T cells ${ }^{56}$.

In summary, our analysis revealed cell-specific differences in global histone methylations and acetylations supported through modulations of one-carbon and acetyl-CoA metabolism, respectively. Furthermore, histone methylations separate immune cells according to their ontogeny and are associated with cellular lifespan and memory.

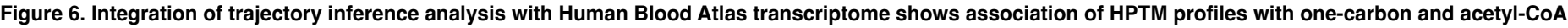
metabolism, cellular lifespan, and immune cell memory.

A-B Methylation trajectory containing all immune cells colored by $\mathbf{A}$ immune cell type and $\mathbf{B}$ cell methylation clusters (MC) shows arbitrarily defined origin of the circular trajectory $(\mathrm{O})$ as the region with the highest proportion of HPCs and MC6 and clusters Ex1 and Ex2.

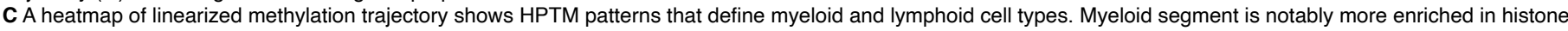

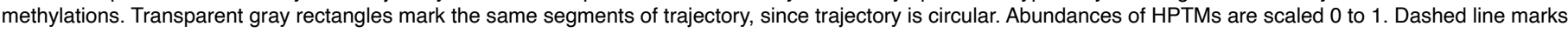
arbitrarily defined origin $(\mathrm{O})$ of the circular trajectory.

D-E Methylation trajectory of NK cells colored by abundance of D CD56 and E CD16 shows D CD56 bright CD16 ${ }^{\text {dim }}$ and E CD56 $6^{\text {dim } C D 16 ~ b r i g h t ~ N K ~ c e l l s . ~}$

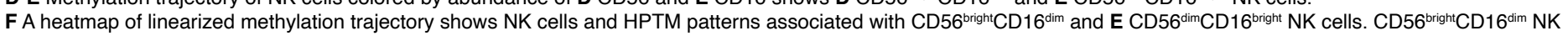

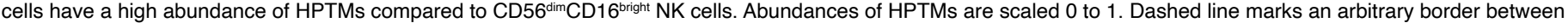
CD56 ${ }^{\text {bright }}$ CD16 $6^{\text {dim }}$ and CD56 ${ }^{\text {dim } C D 16 ~} 6^{\text {bright }}$ NK cells.

G An overview of the one-carbon and acetyl-CoA metabolism includes summary of results from panel I. Reactions of folate and methionine cycles lead to synthesis of S-adenosylmethionine (SAM) that is a substrate for all cellular methylations. Acetyl-CoA is a substrate for cellular acetylations. One-carbon and acetyl-CoA metabolism depend on vitamins B9 (folate), B12 (cobalamin) and B5 (pantothenic acid). These reactions are the "highway" that connects the environment and global epigenetic changes. S-adenosylhomocysteine (SAH), dihydrofolic acid (DHF), tetrahydrofolic acid (THF), coenzyme A (CoA), folate receptor 2 (FOLR2), solute carrier family 19 member 1 (SLC19A1), SLC46A1, methylenetetrahydrofolate reductase (MTHFR), 5,10-methylenetetrahydrofolate (5-10-MTHF), 5-methyltetrahydrofolate (5MTHF), 5-methyltetrahydrofolate-homocysteine methyltransferase (MTR), adenosylhomocysteinase $(A H C Y)$, serine hydroxymethyltransferase 1 (SHMT1), methionine adenosyltransferase $2 \mathrm{~A}(M A T 2 A)$, acyl-CoA synthetase short chain family member 2 (ACSS2)

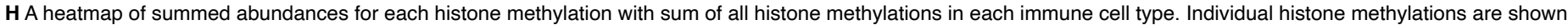
as z-score scaled values.

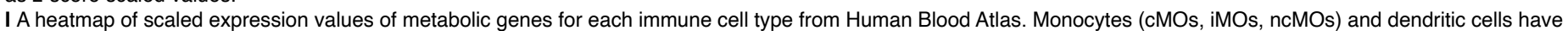
upregulated critical genes in one-carbon and acetyl-CoA metabolism compared to lymphocytes.

$\mathbf{J}-\mathbf{K}$ Acetylation trajectory containing all immune cells colored by $\mathbf{J}$ immune cell type and $\mathbf{K}$ cell acetylation clusters (AC) shows arbitrarily defined origin of the circular trajectory $(\mathrm{O})$ as the region with the highest proportion of HPCs and AC5.

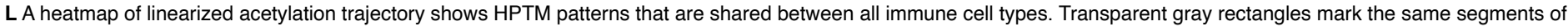
trajectory, since trajectory is circular. Abundances of HPTMs are scaled 0 to 1 . Dashed line marks arbitrarily defined origin (O) of the circular trajectory.

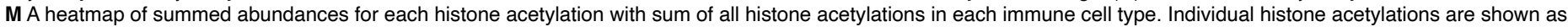
z-score scaled values. 


\section{bioR Xiv}

THE PREPRINT SERVER FOR BIOLOGY

\section{Discussion}

We performed HPTM profiling of almost 28 million PBMCs from 5 independent cohorts of 83 healthy controls, which represented realworld biological heterogeneity, by measuring 37 HPTMs and histone variants across 11 immune cell types. To the best of our knowledge, this is the most comprehensive single cell epigenetic profiling of healthy PBMCs to date. We modelled cross talk between HPTMs using linear and nonlinear analyses to identify (1) HPTM modules conserved across all immune cell types or specific to a cell type, (2) epigenetic heterogeneity at single-cell level, and (3) differences in global histone methylations and acetylations between innate and adaptive immune cells that are associated with metabolism. We found that basal level transcriptional differences in one-carbon metabolism are associated with intrinsic differences in cellular life span and capacity to mount immune memory between innate and adaptive immune cells. Our results establish the reference HPTM landscape of the healthy human immune system and provide the foundation for future studies aimed at identifying perturbed HPTM pathways within immune cells in cancers, vaccines, infections, and autoimmune diseases.

HPTM correlation network analysis identified hub HPTMs, characterized by high betweenness centrality, which suggests that immune cells rely on a handful of hub HPTMs that are highly correlated with the other HPTMs. Irrespective of their different homeostatic physiological functions, each immune cell type shared modules with hub HPTMs involved (1) in activation (H3K4me2/ me3, H3K9me1) and repression (H3K9me2) of gene transcription through chromatin remodeling of transcription start sites (TSSs), or (2) in epigenetic bookmarking ( $\mathrm{H} 4 \mathrm{~K} 5 \mathrm{ac})$ and regulation of distant enhancers (H3K9ac, H3K14ac and H3.3S31ph) $)^{15,16,57,58}$. Therefore, we propose these conserved modules, identified using tens of millions of cells, are strong evidence of conserved coregulation of trans and cis histone pathways. Importantly, the highest centrality of $\mathrm{H} 3 \mathrm{~K} 4 \mathrm{me} 3 / \mathrm{H} 3 \mathrm{~K} 9 \mathrm{me} 2$ in MM1, H3K4me2/H3K9me1 in MM2, and clustering of these HPTMs in trajectory inference analysis, strongly suggest immune cells regulate transcription through a cis bivalent histone methylation signature $\mathrm{H} 3 \mathrm{~K} 4 \mathrm{me} 3-\mathrm{K} 9 \mathrm{me} 3 / 2^{59-61}$. This bivalent signature has not been described before in any immune cell type. Considering the robustness of our results and recent advances in targeting lysine demethylases $K D M 7 B$ and $K D M 4 A$, which modulate these two HPTMs, with small molecule inhibitors, further studies should focus on understanding their functions ${ }^{62-64}$.

Proteolytic cleavage of $\mathrm{H} 3$ histone at threonine 22 (cleaved H3T22) physically removes histone tails including $\mathrm{N}$ terminal end up to $\mathrm{K} 27^{19}$. However, we discovered positive correlations between cleaved H3T22 and H3K9ac, H3S10ph, H3K14ac, H3K18ac, and $\mathrm{H} 3.3 \mathrm{~S} 31 \mathrm{ph}$. Of these HPTMs, all but H3.3S31ph cannot occur if the histone tail is physically removed, thus it seems $\mathrm{H} 3 \mathrm{~K} 9 \mathrm{ac}$, H3S10ph, H3K14ac, and H3K18ac are introduced in chromatin through independent $\mathrm{H} 3$ tails but during proteolytic cleavage. Interestingly, cleaved H3T22 had no or weak correlation with H3K23ac and H3K27ac, suggesting acetylations around the cleavage site (K23, K27) either block proteolysis or H3K23ac and $\mathrm{H} 3 \mathrm{~K} 27 \mathrm{ac}$ are involved in the establishment of the open chromatin once proteolytic activity decreased. Functional role of acetylation at $\mathrm{H} 3 \mathrm{~K} 23$, aside from constituting open chromatin, is poorly
ARTICLE PREPRINT

understood; thus, further investigation is needed especially in conjunction with cleaved $\mathrm{H} 3$.

In lineage specific HPTM modules, hub HPTMs were involved in direct regulation of active transcription (e.g., H3K36me3 in MM4 and H3.3 in MM5). Both correlation analysis and trajectory inference found that when cMOs, ncMOs, and iMOs increase H3K36me 3 or H3.3, other histone methylation marks are concurrently removed from the histone tails. $\mathrm{H} 3 \mathrm{~K} 36 \mathrm{me} 3$ prevents random positioning of RNA pol II during transcription and occurrence of faulty transcripts through transcription elongation ${ }^{49,65,66}$. Further, because nucleosomes are assembled in pairs of histone dimers, i.e., H3-H4 and H2A$\mathrm{H} 2 \mathrm{~B}$, it is reasonable to conclude that cells swap modified pairs of canonical H3-H4 with the newly synthetized H3.3-H4 pairs $^{67}$. Such a dramatic chromatin remodeling, mostly in cMOs, ncMOs, and iMOs, has not been reported before, and is likely an indication of their differentiation in blood ${ }^{50}$. Overall, our data support a model in which cells remove other HPTMs that may promote transcription, further suggesting strict compartmentalization between gene regulation and transcription.

We defined HPCs as Lin-CD34+ PBMCs. However, CD34 is not exclusively expressed in hematopoietic stem cells but is also expressed in more differentiated cells, including CMPs, CLPs, and MEPs ${ }^{68}$. Hence, HPCs in blood are a mixture of different progenitors. Trajectory analysis followed by clustering of PBMCs identified epigenetically distinct subpopulations of HPCs, including H3K36me $1^{+}$HPCs $(6.9 \%$ of total HPCs) and H3K36me $1^{-}$HPCs (2\% of total HPCs) using the methylation panel, and $\mathrm{H} 3 \mathrm{~K} 14 \mathrm{ac}^{+} \mathrm{H} 4 \mathrm{~K} 5 \mathrm{ac}^{-} \mathrm{HPCs}(13.7 \%$ of total HPCs) and $\mathrm{H} 3 \mathrm{~K} 14 \mathrm{ac}^{-} \mathrm{H} 4 \mathrm{~K}^{2} \mathrm{ac}^{+} \mathrm{HPCs}(1.6 \%$ of total HPCs) using the acetylation panel. Importantly, these subpopulations were phenotypically defined as $\mathrm{CD} 45^{\mathrm{dim}} \mathrm{CD} 34^{\mathrm{dim}}$ HPCs. Since more pluripotent HPCs are considered $\mathrm{CD} 45^{\mathrm{dim}} \mathrm{CD} 34^{\mathrm{dim}}{ }^{69,70}$, our data suggest high abundances of $\mathrm{H} 3 \mathrm{~K} 9 \mathrm{me} 2, \mathrm{H} 3 \mathrm{~K} 36 \mathrm{me} 1, \mathrm{H} 3 \mathrm{~K} 14 \mathrm{ac}$, and $\mathrm{H} 4 \mathrm{~K} 5 \mathrm{ac}$ in $\mathrm{CD} 45^{\mathrm{dim}} \mathrm{CD} 34^{\mathrm{dim}}$ HPCs may be the hallmarks of bona fide hematopoietic stem cells. These results further highlight the complementary advantage of EpiTOF compared to ChIP-seq, which cannot identify this heterogeneity in a rare population, and ATACseq, which can identify the heterogeneity but not the combination of HPTMs that lead to observed chromatin accessibility.

Trajectory inference analysis, integrated with transcriptome data, strongly associated HPTM profiles with one-carbon metabolism, cellular lifespan, and immune cell memory, several of which have been mechanistically demonstrated in other biological systems ${ }^{43-46,71-80}$. We found myeloid and CD56 $6^{\text {bright }} \mathrm{CD} 16^{\text {dim }} \mathrm{NK}$ cells have higher histone methylations than $\mathrm{T}$, B or $\mathrm{CD} 56^{\mathrm{dim}} \mathrm{CD} 16^{\text {bright }}$ NK cells. Transcriptomics data corroborated myeloid cells with increased histone methylations support high turnover of various histone methylations through SAM synthesis ${ }^{81}$, which is energetically expensive to maintain for a longer time. Difference in lifespan between cytokine producing $\left(\mathrm{CD} 56^{\text {bright }} \mathrm{CD} 16^{\mathrm{dim}}\right)$ and memory (CD56 $\left.6^{\mathrm{dim}} \mathrm{CD} 16^{\text {bright }}\right) \mathrm{NK}$ cells stems from a necessary expression of recombination activating $1(R A G l)$ and $R A G 2$ in longer-lived memory, but not cytokine producing NK cells ${ }^{36,37}$. $R A G 1$ and $R A G 2$ are also essential for the differentiation of $\mathrm{B}$ and $T$ cells, both of which have memory and longer lifespan than other immune cells ${ }^{34-36,44}$. Interestingly, studies in fish found Ragl- 
bioRxiv preprint doi: https://doi.org/10.1101/2022.01.21.477300; this version posted January 23, 2022. The copyright holder for this preprint (which was not certified by peer review) is the author/funder. All rights reserved. No reuse allowed without permission.

\section{bioR Xiv}

immunodeficiency induces premature aging and shortens life span, supporting that $R A G 1 / R A G 2$ have a role in extension of the life $\operatorname{span}^{82}$. However, existing evidence is insufficient to decipher whether the state of low histone methylations is in response to or a driving factor behind the extended life span, warranting future studies addressing mechanisms and causations.

Our study has a few limitations. First, our analysis inferred several novel cis and trans associations between HPTMs and confirmed several previously described associations and causal relations between HPTMs. These novel associations should be further investigated in mechanistic studies. Reproducibility of these novel associations and cellular heterogeneity across five independent cohorts provide robust evidence in support of further mechanistic studies. For instance, we recently reported epigenetic mechanisms of monocyte differentiation into macrophages, which demonstrated relationships between several HPTMs ${ }^{83}$. Second, EpiTOF lacks locus-specific information, unlike ChIP-seq and ATAC-seq. However, integration of EpiTOF, scATAC-seq and CITE-seq/ scRNA-seq would enhance our understanding of epigenetic processes by identifying a combination of HPTMs that is associated with chromatin accessibility or transcriptome profile in a given cell type during different immunological states. Hence, EpiTOF is an important tool to start mapping at single cell resolution multilayered information coming from chromatin remodeling, transcriptomics, and proteomics.

Overall, our study has long-term implications for immunology, developmental biology, and epigenetics. Our data demonstrated that HPTMs are regulated globally within a cell in a modular fashion, which can be further studied using epigenetic trajectory inference to investigate order of histone modifications in a cell type-specific manner at s single-cell resolution. Most importantly, our study provides a high-resolution reference landscape to start decoding the histone language of the healthy human immune system.

\section{Contributions}

PK conceived the study. PK and PJU obtained funding. DD, LK, AG, and MDo performed computational analyses, and interpreted data. PJU supervised EpiTOF profiling. DD and PK wrote the manuscript with contributions from all coauthors. AK, PC, SC, and MDv performed EpiTOF profiling. TJS enrolled adolescents in South Africa. AH enrolled adults in the Stanford cohort. PK and PJU supervised the study. All authors approved the manuscript.

\section{Disclosures}

PK is funded in part by the Bill and Melinda Gates Foundation (OPP1113682); the National Institute of Allergy and Infectious Diseases (NIAID) grants 1U19AI109662, U19AI057229, and 5R01AI125197; Department of Defense contracts W81XWH-18-1-0253 and W81XWH1910235; and the Ralph \& Marian Falk Medical Research Trust. PJU is supported in part by the Donald E. and Delia B. Baxter Foundation, Elizabeth F. Adler, the Henry Gustav Floren Trust, the Bill \& Melinda Gates Foundation (OPP1113682), and the NIH grants U19 AI110491 (Autoimmunity Center of Excellence), R01 AI125197.

\section{References}

1. Erdel, F. \& Rippe, K. Formation of Chromatin Subcompartments by Phase Separation. Biophys J 114, 2262-2270 (2018).

2. Lee, J.-S., Smith, E. \& Shilatifard, A. The Language of Histone Crosstalk. Cell 142, $682-685(2010)$

3. Fingerman, I. M., Du, H.-N. \& Briggs, S. D. Controlling histone methylation via transhistone pathways. Epigenetics 3, 237-242 (2008).

4. Fischle, W. Talk is cheap - cross-talk in establishment, maintenance, and readout of chromatin modifications. Gene Dev 22, 3375-3382 (2008).

\section{ARTICLE PREPRINT}

5. Walter, W. et al. 14-3-3 interaction with histone $\mathrm{H} 3$ involves a dual modification pattern of phosphoacetylation. Mol Cell Biol 28, 2840-9 (2008).

6. Rea, S. et al. Regulation of chromatin structure by site-specific histone $\mathrm{H} 3$ methyltransferases. Nature 406, 593-599 (2000).

7. Lee, J.-S. et al. Histone Crosstalk between H2B Monoubiquitination and H3 Methylation Mediated by COMPASS. Cell 131, 1084-1096 (2007).

8. McGinty, R. K., Kim, J., Chatterjee, C., Roeder, R. G. \& Muir, T. W. Chemically ubiquitylated histone H2B stimulates hDot1L-mediated intranucleosomal methylation. Nature 53, 812-816 (2008)

9. Weake, V. M. \& Workman, J. L. Histone Ubiquitination: Triggering Gene Activity. Mol Cell 29, 653-663 (2008).

10. Weiner, A. et al. Co-ChIP enables genome-wide mapping of histone mark co-occurrence at single-molecule resolution. Nat Biotechnol 34, 953-961 (2016).

11. Rotem, A. et al. Single-cell ChIP-seq reveals cell subpopulations defined by chromatin state. Nat Biotechnol 33, 1165-1172 (2015).

12. Grosselin, K. et al. High-throughput single-cell ChIP-seq identifies heterogeneity of chromatin states in breast cancer. Nat Genet 51, 1060-1066 (2019).

13. Cheung, P. et al. Single-Cell Chromatin Modification Profiling Reveals Increased Epigenetic Variations with Aging. Cell 173, 1385-1397.e14 (2018).

14. Bernstein, B. E. et al. Genomic Maps and Comparative Analysis of Histone Modifications in Human and Mouse. Cell 120, 169-181 (2005).

15. Barski, A. et al. High-Resolution Profiling of Histone Methylations in the Human Genome Cell 129, 823-837 (2007)

16. Armache, A. et al. Histone H3.3 phosphorylation amplifies stimulation-induced transcription. Nature 583, 852-857 (2020).

17. Gates, L. A. et al. Acetylation on histone $\mathrm{H} 3$ lysine 9 mediates a switch from transcription initiation to elongation. J Biol Chem 292, 14456-14472 (2017).

18. Wang, Z. et al. Combinatorial patterns of histone acetylations and methylations in the human genome. Nat Genet 40, 897-903 (2008)

19. Duncan, E. M. et al. Cathepsin L proteolytically processes histone H3 during mouse embryonic stem cell differentiation. Cell 135, 284-94 (2008).

20. Brehove, M. et al. Histone Core Phosphorylation Regulates DNA Accessibility*. J Biol Chem 290, 22612-22621 (2015)

21. Komar, D. \& Juszczynski, P. Rebelled epigenome: histone H3S10 phosphorylation and H3S10 kinases in cancer biology and therapy. Clin Epigenetics 12, 147 (2020).

22. Wagner, E. J. \& Carpenter, P. B. Understanding the language of Lys 36 methylation at histone H3. Nat Rev Mol Cell Bio 13, 115-126 (2012).

23. Patel, A. A. et al. The fate and lifespan of human monocyte subsets in steady state and systemic inflammation. $J$ Exp Med 214, 1913-1923 (2017).

24. Wong, L. H. et al. Histone H3.3 incorporation provides a unique and functionally essential telomeric chromatin in embryonic stem cells. Genome Res 19, 404-14 (2009).

25. Jang, C.-W., Shibata, Y., Starmer, J., Yee, D. \& Magnuson, T. Histone H3.3 maintains genome integrity during mammalian development. Gene Dev 29, 1377-1392 (2015).

26. Levine, J. H. et al. Data-Driven Phenotypic Dissection of AML Reveals Progenitor-like Cells that Correlate with Prognosis. Cell 162, 184-197 (2015).

27. Dermadi, D. et al. Exploration of Cell Development Pathways through High-Dimensional Single Cell Analysis in Trajectory Space. Iscience 23, 100842 (2020).

28. Bernstein, B. E. et al. A Bivalent Chromatin Structure Marks Key Developmental Genes in Embryonic Stem Cells. Cell 125, 315-326 (2006).

29. Araki, Y. et al. Genome-wide Analysis of Histone Methylation Reveals Chromatin StateBased Regulation of Gene Transcription and Function of Memory CD8+ T Cells. Immunity 30 , 912-925 (2009)

30. Nguyen, M. L. T., Jones, S. A., Prier, J. E. \& Russ, B. E. Transcriptional Enhancers in the Regulation of T Cell Differentiation. Front Immunol 6, 462 (2015).

31. Stairiker, C. J., Thomas, G. D. \& Salek-Ardakani, S. EZH2 as a Regulator of CD8+ T Cell Fate and Function. Front Immunol 11, 593203 (2020).

32. Francastel, C., Schübeler, D., Martin, D. I. K. \& Groudine, M. Nuclear compartmentalization and gene activity. Nat Rev Mol Cell Bio 1, 137-143 (2000).

33. Grigoryev, S. A., Nikitina, T., Pehrson, J. R., Singh, P. B. \& Woodcock, C. L. Dynamic relocation of epigenetic chromatin markers reveals an active role of constitutive heterochromatin in the transition from proliferation to quiescence. J Cell Sci 117, 6153-6162 (2004).

34. Nagler, A., Lanier, L. L., Cwirla, S. \& Phillips, J. H. Comparative studies of human FcRIIIpositive and negative natural killer cells. J Immunol Baltim Md 1950 143, 3183-91 (1989)

35. Amand, M. et al. Human CD56dimCD16dim Cells As an Individualized Natural Killer Cell Subset. Front Immunol 8, 699 (2017). 
bioRxiv preprint doi: https://doi.org/10.1101/2022.01.21.477300; this version posted January 23, 2022. The copyright holder for this preprint (which was not certified by peer review) is the author/funder. All rights reserved. No reuse allowed without permission.

\section{bioR Xiv}

THE PREPRINT SERVER FOR BIOLOGY

36. Karo, J. M., Schatz, D. G. \& Sun, J. C. The RAG Recombinase Dictates Functional Heterogeneity and Cellular Fitness in Natural Killer Cells. Cell 159, 94-107 (2014).

37. Peng, H. \& Tian, Z. Natural Killer Cell Memory: Progress and Implications. Front Immunol 8, 1143 (2017).

38. Poli, A. et al. CD56brightnatural killer (NK) cells: an important NK cell subset. Immunology 126, 458-465 (2009)

39. Fulcher, D. \& Basten, A. B cell life span: A review. Immunol Cell Biol 75, 446-455 (1997) 40. Vrisekoop, N. et al. Sparse production but preferential incorporation of recently produced naive T cells in the human peripheral pool. Proc National Acad Sci 105, 6115-6120 (2008).

41. Gossel, G., Hogan, T., Cownden, D., Seddon, B. \& Yates, A. J. Memory CD4 T cell subsets are kinetically heterogeneous and replenished from naive T cells at high levels. Elife 6, e23013 (2017)

42. Janssen, W. J., Bratton, D. L., Jakubzick, C. V. \& Henson, P. M. Myeloid Cells in Health and Disease. Microbiol Spectr 4, 99-115 (2017).

43. Serefidou, M., Venkatasubramani, A. V. \& Imhof, A. The Impact of One Carbon Metabolism on Histone Methylation. Frontiers Genetics 10, 764 (2019).

44. Froese, D. S., Fowler, B. \& Baumgartner, M. R. Vitamin B12, folate, and the methionine remethylation cycle-biochemistry, pathways, and regulation. J Inherit Metab Dis 42, 673-685 (2018).

45. Cabreiro, F. et al. Metformin Retards Aging in C. elegans by Altering Microbial Folate and Methionine Metabolism. Cell 153, 228-239 (2013).

46. Parkhitko, A. A., Jouandin, P., Mohr, S. E. \& Perrimon, N. Methionine metabolism and methyltransferases in the regulation of aging and lifespan extension across species. Aging Cell 18, (2019).

47. Uhlen, M. et al. Towards a knowledge-based Human Protein Atlas. Nat Biotechnol 28, $1248-1250(2010)$

48. Zhao, R. \& Goldman, I. D. Folate and thiamine transporters mediated by facilitative carriers (SLC19A1-3 and SLC46A1) and folate receptors. Mol Aspects Med 34, 373-385 (2013).

49. Neri, F. et al. Intragenic DNA methylation prevents spurious transcription initiation. Nature 543, 72-77 (2017)

50. Sugimoto, C. et al. Differentiation Kinetics of Blood Monocytes and Dendritic Cells in Macaques: Insights to Understanding Human Myeloid Cell Development. J Immunol 195, 1774-1781 (2015)

51. Wu, S. \& Rice, J. C. A new regulator of the cell cycle. Cell Cycle 10, 68-72 (2014).

52. Eberharter, A. \& Becker, P. B. Histone acetylation: a switch between repressive and permissive chromatin: Second in review series on chromatin dynamics. Embo Rep 3, 224-229 (2002).

53. Pietrocola, F., Galluzzi, L., Bravo-San Pedro, J. M., Madeo, F. \& Kroemer, G. Acetyl Coenzyme A: A Central Metabolite and Second Messenger. Cell Metab 21, 805-821 (2015).

54. Raisner, R. et al. Enhancer Activity Requires CBP/P300 Bromodomain-Dependent Histone H3K27 Acetylation. Cell Reports 24, 1722-1729 (2018).

55. Vempati, R. K. et al. p300-mediated Acetylation of Histone H3 Lysine 56 Functions in DNA Damage Response in Mammals*. J Biological Chem 285, 28553-28564 (2010).

56. Gasser, S. \& Raulet, D. H. The DNA Damage Response Arouses the Immune System. Cancer Res 66, 3959-3962 (2006).

57. Zhao, R., Nakamura, T., Fu, Y., Lazar, Z. \& Spector, D. L. Gene bookmarking accelerates the kinetics of post-mitotic transcriptional re-activation. Nat Cell Biol 13, 1295-1304 (2011).

58. Martire, S. et al. Phosphorylation of histone H3.3 at serine 31 promotes $\mathrm{p} 300$ activity and enhancer acetylation. Nat Genet 51, 941-946 (2019).

59. Huang, Y., Fang, J., Bedford, M. T., Zhang, Y. \& Xu, R.-M. Recognition of Histone H3 Lysine-4 Methylation by the Double Tudor Domain of JMJD2A. Science 312, 748-751 (2006). 60. Feng, W., Yonezawa, M., Ye, J., Jenuwein, T. \& Grummt, I. PHF8 activates transcription of rRNA genes through H3K4me3 binding and H3K9me1/2 demethylation. Nat Struct Mol Biol 17, 445-450 (2010).

61. Matsumura, Y. et al. H3K4/H3K9me3 Bivalent Chromatin Domains Targeted by LineageSpecific DNA Methylation Pauses Adipocyte Differentiation. Mol Cell 60, 584-596 (2015).

62. Suzuki, T. et al. Identification of the KDM2/7 Histone Lysine Demethylase Subfamily Inhibitor and its Antiproliferative Activity. J Med Chem 56, 7222-7231 (2013).

63. Bhushan, B. et al. Investigations on small molecule inhibitors targeting the histone H3K4 tri-methyllysine binding PHD-finger of JmjC histone demethylases. Bioorgan Med Chem 26, 2984-2991 (2018).

64. Lin, H. et al. Small molecule KDM4s inhibitors as anti-cancer agents. J Enzym Inhib Med Ch 33, 777-793 (2018).

65. DiFiore, J. V. et al. Unique and Shared Roles for Histone H3K36 Methylation States in Transcription Regulation Functions. Cell Reports 31, 107751 (2020).

66. Teissandier, A. \& Bourc'his, D. Gene body DNA methylation conspires with H3K36me3 to

\section{ARTICLE PREPRINT}

preclude aberrant transcription. Embo J 36, 1471-1473 (2017).

67. Böhm, V. et al. Nucleosome accessibility governed by the dimer/tetramer interface. Nucleic Acids Res 39, 3093-3102 (2011)

68. Chao, M. P., Seita, J. \& Weissman, I. L. Establishment of a Normal Hematopoietic and Leukemia Stem Cell Hierarchy. Cold Spring Harb Sym 73, 439-449 (2008).

69. Morrison, S. J. \& Weissman, I. L. The long-term repopulating subset of hematopoietic stem cells is deterministic and isolatable by phenotype. Immunity 1, 661-673 (1994).

70. Osawa, M., Hanada, K., Hamada, H. \& Nakauchi, H. Long-Term Lymphohematopoietic Reconstitution by a Single CD34-Low/Negative Hematopoietic Stem Cell. Science 273, 242-245 (1996)

71. Pike, M. C., Kredich, N. M. \& Snyderman, R. Requirement of S-adenosyl-L-methioninemediated methylation for human monocyte chemotaxis. Proc National Acad Sci 75, 3928-3932 (1978)

72. Donohoe, D. R. \& Bultman, S. J. Metaboloepigenetics: Interrelationships between energy metabolism and epigenetic control of gene expression. J Cell Physiol 227, 3169-3177 (2012).

73. Kaelin, W. G. \& McKnight, S. L. Influence of Metabolism on Epigenetics and Disease. Cell 153, 56-69 (2013)

74. Tzika, E., Dreker, T. \& Imhof, A. Epigenetics and Metabolism in Health and Disease. Frontiers Genetics 9, 361 (2018)

75. Samblas, M., Martínez, J. A. \& Milagro, F. Folic Acid Improves the Inflammatory Response in LPS-Activated THP-1 Macrophages. Mediat Inflamm 2018, 1-8 (2018).

76. Trefely, S., Doan, M. T. \& Snyder, N. W. Crosstalk between cellular metabolism and histone acetylation. Methods Enzymol 1-21 (2019) doi:10.1016/bs.mie.2019.07.013.

77. Yu, W. et al. One-Carbon Metabolism Supports S-Adenosylmethionine and Histone Methylation to Drive Inflammatory Macrophages. Mol Cell 75, 1147-1160.e5 (2019).

78. Sinclair, L. V. et al. Antigen receptor control of methionine metabolism in T cells. Elife $\mathbf{8}$ e44210 (2019).

79. Zhu, X. et al. Frontline Science: Monocytes sequentially rewire metabolism and bioenergetics during an acute inflammatory response. J Leukocyte Biol 105, 215-228 (2019).

80. Dai, Z., Ramesh, V. \& Locasale, J. W. The evolving metabolic landscape of chromatin biology and epigenetics. Nat Rev Genet 21, 737-753 (2020).

81. Su, X., Wellen, K. E. \& Rabinowitz, J. D. Metabolic control of methylation and acetylation. Curr Opin Chem Biol 30, 52-60 (2016).

82. Novoa, B. et al. Rag1 immunodeficiency-induced early aging and senescence in zebrafis are dependent on chronic inflammation and oxidative stress. Aging Cell 18, e13020 (2019).

83. Cheung, P. et al. Repression of CTSG, ELANE and PRTN3-mediated histone H3 proteolytic cleavage promotes monocyte-to-macrophage differentiation. Nat Immunol 22, 711-722 (2021). 